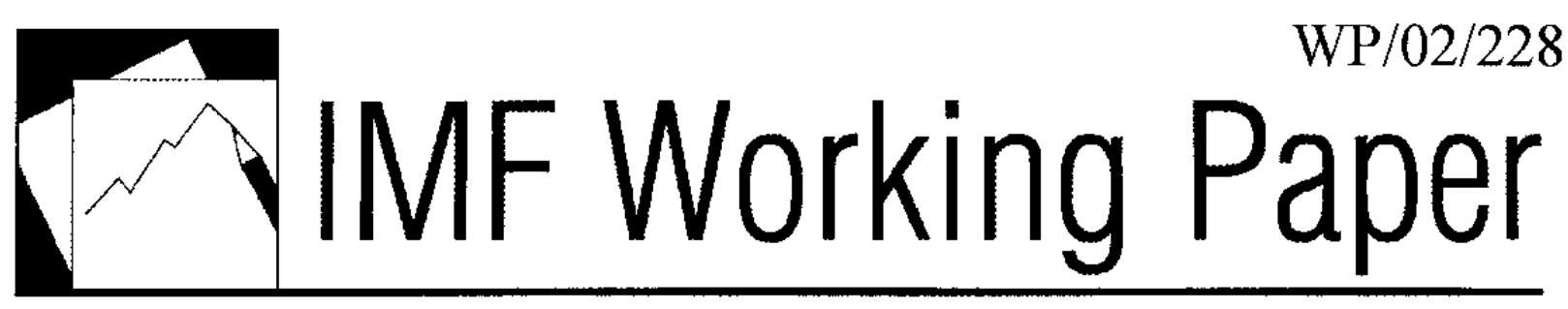

\title{
Why Do Many Disinflations Fail? The Importance of Luck, Timing, and Political Institutions
}

A. Javier Hamann and Alessandro Prati 


\title{
IMF Working Paper
}

Policy Development and Review Department and

Research Department

\section{Why Do Many Disinflations Fail? \\ The Importance of Luck, Timing, and Political Institutions}

\author{
Prepared by A. Javier Hamann and Alessandro Prati ${ }^{1}$ \\ Authorized for distribution by Marianne Schulze-Ghattas and Ratna Sahay
}

December 2002

\begin{abstract}
The views expressed in this Working Paper are those of the author(s) and do not necessarily represent those of the IMF or IMF policy. Working Papers describe research in progress by the author(s) and are published to elicit comments and to further debate.
\end{abstract}

Many inflation stabilizations succeed only temporarily. Using a sample of 51 episodes of stabilization from inflation levels above 40 percent, we show that most of the failures are explained by bad luck, unfavorable initial conditions, and inadequate political institutions. The evolution of trading partners' demand and U.S. interest rates captures the effect of bad luck. Past inflation affects the outcome in two different ways: a long history of high inflation makes failure more likely, while a high level of inflation prior to stabilization increases the chances of success. Countries with short-lived political institutions, a weak executive authority, and proportional electoral rules also tend to fail. After controlling for all these factors, we find that exchange--rate-based stabilizations are more likely to succeed. These findings are robust across measures of failure (two dichotomous and one continuous), sample selection criteria, and estimation techniques, including Heckman's correction for the endogeneity of the anchor.

JEL Classification Numbers:E31, E63

Keywords: Disinflation, stabilization

Authors' E-Mail Addresses: ahamann@imf.org; aprati@imf.org

\footnotetext{
${ }^{1} \mathrm{We}$ are indebted to Susan Collins for valuable suggestions at an early stage of this paper; to Holger Wolf, Miguel Savastano, and participants at seminars at the IMF and the Central Bank of Peru for helpful comments; and to Guido Tabellini for providing data on political systems.
} 


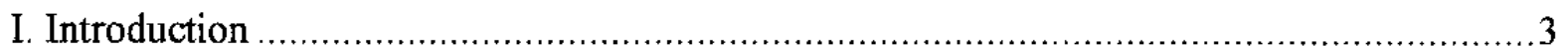

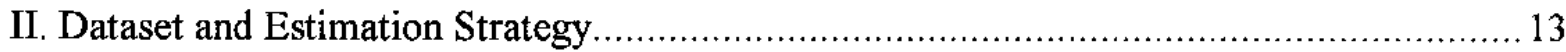

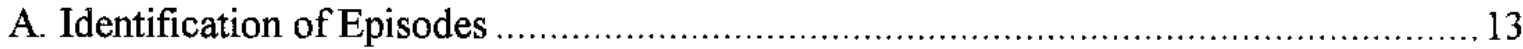

B. Sample Selection and Scope of Our Study ........................................................... 14

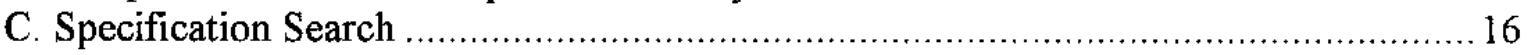

D. Measuring Failure

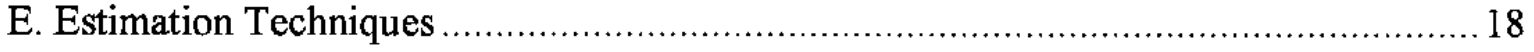

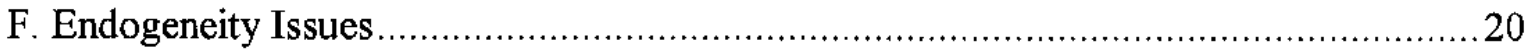

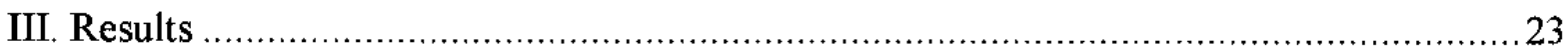

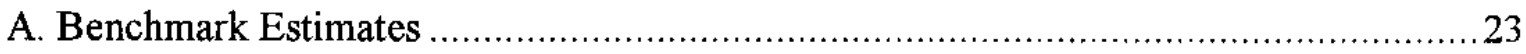

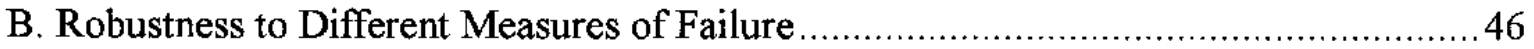

C. Robustness to Different Sample Selection Criteria .............................................50

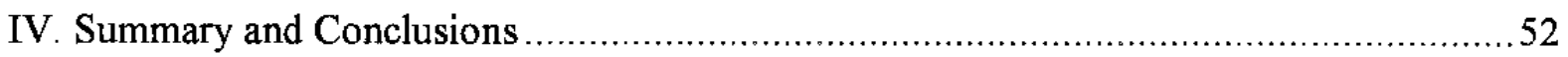

Appendices

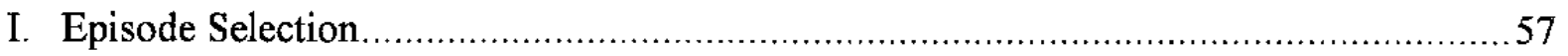

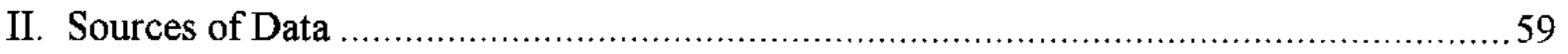

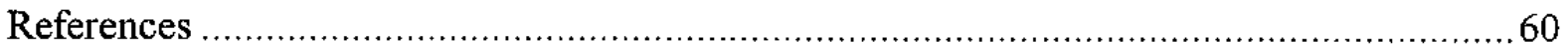

\section{Text Tables}

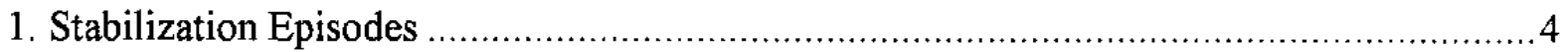

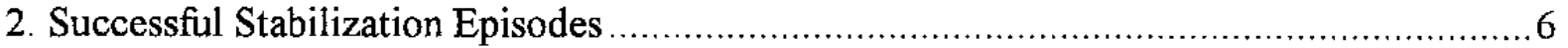

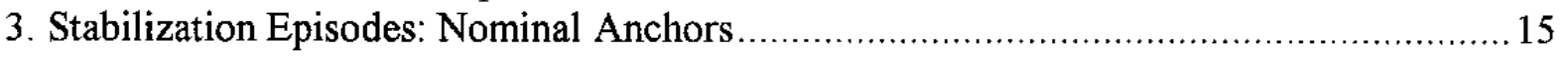

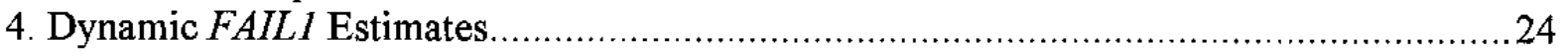

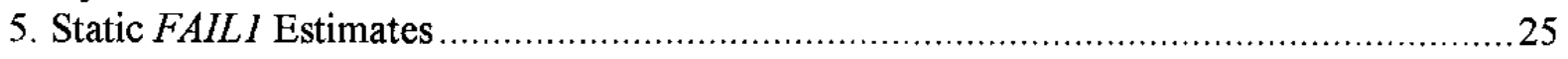

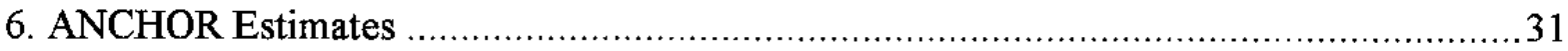

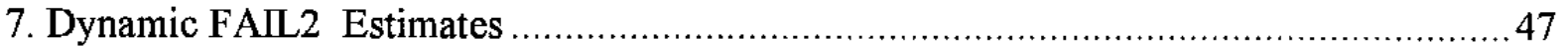

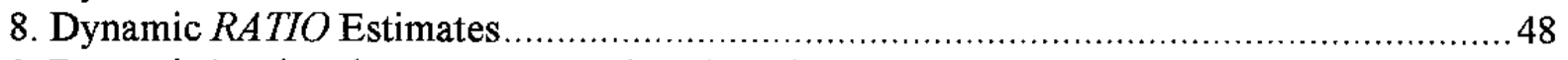

9. Dynamic Pool Estimates on Easterly's (1996) Sample .................................................51

Figures

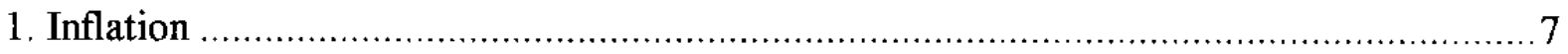

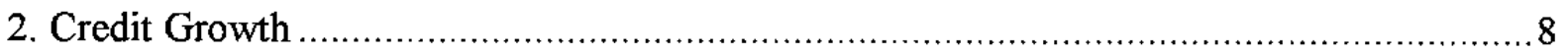

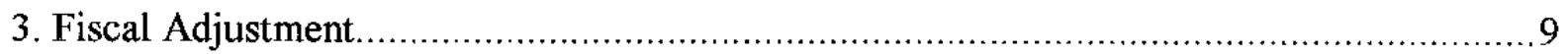

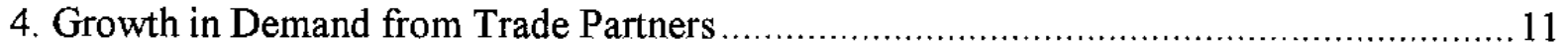

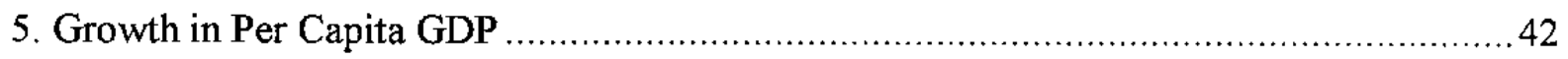

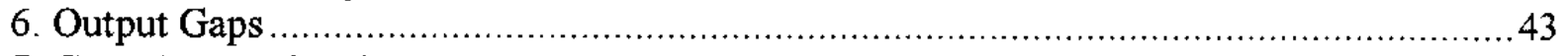

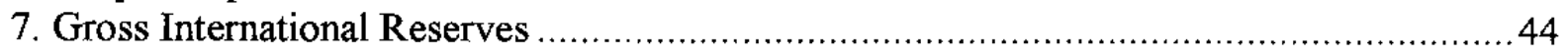




\section{INTRODUCTION}

Countries experiencing high inflation typically embark on several disinflation attempts, most of which enjoy only temporary success. In this paper we study why initial disinflation gains tend to be short-lived in a sample of 51 high-inflation stabilizations that satisfy a criterion of minimum initial success. The focus on durability distinguishes our analysis from the rest of the literature on disinflation. The scope of our study-in terms of sample size and the set of questions addressed-is also broader than in the existing literature. Specifically, we go beyond identifying an association between failure and insufficient monetary and fiscal adjustment and examine the role of underlying factors such as external shocks, initial conditions (including the choice of the nominal anchor and the degree of openness of the economy), and political institutions.

In recent years, most of the literature on disinflation has concentrated on whether the post-stabilization path of key macroeconomic variables--such as GDP growth, private consumption, the real exchange rate, and the current account of the balance of paymentsdepends on the nominal anchor used in the disinflation strategy. ${ }^{2}$.The focus of attention has been whether exchange rate-based stabilizations (ERBS), as opposed to money-based stabilizations, generate a distinctive economic cycle. We study, instead, whether the initial inflation reductions were lasting. ${ }^{3}$ Several were not: in 30 to 60 percent (depending on the criterion used to measure failure) of the episodes in our sample, the initial gains in disinflation were lost by the third year following stabilization.

The scope of this paper is broader than that of previous studies. Our sample of inflation stabilization episodes, comprising 51 stabilizations (Table 1), is larger than those used in other empirical studies. These previous studies are typically based on a sample of episodes that are either well-documented in the literature or identified through a numerical rule consisting of an absolute threshold for the level of inflation (i.e., a reduction in inflation-no matter how large-is not considered a "stabilization" if inflation does not breach the threshold). ${ }^{4}$ The sample used here is selected with a numerical rule that requires

\footnotetext{
${ }^{2}$ See Calvo and Végh (1999) for a comprehensive review of the literature.

${ }^{3}$ To the best of our knowledge, Veiga (1999) represents the only attempt at identifying empirically the determinants of a successful disinflation strategy. However, his paper takes a view of stabilizations that is heavily influenced by ERBS, and uses a sample comprised mostly of ERBS ( 29 out of a total of 34 episodes).
}

${ }^{4}$ Veiga (1999) appears to contain the largest number of episodes of any study based on the compilation of documented cases: 34 . The studies by Kiguel and Liviathan (1992), Calvo and Végh (1994) and Reinhart and Végh (1994) are based on less than 20 episodes. Studies based on a numerical rule include Easterly (1996), which identifies 28 episodes, and Fischer, Sahay and Végh (2002), which includes 49 cases. 
Table 1. Stabilization Episodes

\begin{tabular}{|c|c|c|c|c|c|}
\hline & \multicolumn{2}{|c|}{ Easterly (1996) } & \multicolumn{2}{|c|}{ Hamann (2001) } & \multirow[b]{2}{*}{$\begin{array}{c}\text { ERBS historical } \\
\text { dates } 1 /\end{array}$} \\
\hline & Date & $\begin{array}{c}\text { Exchange rate } \\
\text { anchor }\end{array}$ & Date & $\begin{array}{c}\text { Exchange rate } \\
\text { anchor }\end{array}$ & \\
\hline Argentina 1 & & & 1977 & & \\
\hline Argentina 2 & & & 1980 & Yes & 1979 \\
\hline Argentina 3 & & & 1986 & Yes & 1985 \\
\hline Argentina 4 & 1990 & Yes & 1991 & Yes & 1991 \\
\hline Bangladesh & 1975 & & 1975 & & \\
\hline Bolivia & 1986 & & 1986 & & \\
\hline Brazil 1 & 1965 & Yes & 1966 & Yes & 1964 \\
\hline Brazil 2 & & & 1991 & & \\
\hline Chile 1 & & & 1965 & & \\
\hline Chile 2 & 1974 & & 1975 & & \\
\hline Congo, Democratic Republic of 1 & & & 1969 & & \\
\hline Congo, Democratic Republic of 2 & & & 1980 & & \\
\hline Congo, Democratic Republic of 3 & 1984 & & 1985 & & \\
\hline Costa Rica & 1983 & & 1983 & & \\
\hline Dominican Republic & 1991 & & 1992 & & \\
\hline Ecuador 1 & & & 1990 & & \\
\hline Ecuador 2 & 1993 & Yes & 1994 & Yes & 1993 \\
\hline Ghana 1 & & & 1978 & & \\
\hline Ghana 2 & 1984 & & 1985 & & \\
\hline Guinea & & & 1988 & & \\
\hline Guinea-Bissau 1 & & & 1990 & & \\
\hline Guinea-Bissau 2 & 1993 & & 1993 & & \\
\hline Guyana & & & 1992 & & \\
\hline Iceland 1 & 1975 & & 1976 & & \\
\hline Iceland 2 & 1984 & Yes & 1984 & Yes & 1983 \\
\hline Indonesia & 1967 & & 1967 & & \\
\hline Israel & 1985 & Yes & 1986 & Yes & 1986 \\
\hline Jamaica & 1992 & & 1993 & & \\
\hline Lebanon 1 & & & 1988 & & \\
\hline Lebanon 2 & & & 1993 & & \\
\hline Mexico 1 & & & 1984 & & \\
\hline Mexico 2 & 1988 & Yes & 1989 & Yes & 1988 \\
\hline Mozambique & & & 1988 & & \\
\hline Nicaragua & 1991 & Yes & 1991 & Yes & 1991 \\
\hline Nigeria & 1989 & & 1990 & & \\
\hline Peru 1 & & & 1986 & Yes & 1986 \\
\hline Peru 2 & 1991 & & 1991 & & \\
\hline São Tomé \& Príncipe & & & 1992 & & \\
\hline Sierra Leone 1 & & & 1988 & & \\
\hline Sierra Leone 2 & 1992 & & 1992 & & \\
\hline Somalia 1 & 1981 & & 1982 & & \\
\hline Somalia 2 & 1985 & & 1985 & & \\
\hline Syrian Arab Republic & & & 1988 & & \\
\hline Turkey & 1981 & & 1981 & & \\
\hline Uganda 1 & 1981 & & 1982 & & \\
\hline Uganda 2 & 1988 & & 1989 & & \\
\hline Uruguay 1 & 1968 & Yes & 1969 & Yes & 1968 \\
\hline Uruguay 2 & & & 1976 & & \\
\hline Uruguay 3 & 1980 & Yes & 1981 & Yes & 1979 \\
\hline Uruguay 4 & & & 1992 & Yes & 1991 \\
\hline Zambia & & & 1994 & & \\
\hline Total number of episodes & 28 & & 51 & & \\
\hline Exchange rate-based stabilizations & & 9 & & 13 & \\
\hline
\end{tabular}

Sources: Easterly (1996), and Hamann (2001).

1/ Year in which exchange rates were actually pegged, if peg ocurred within the first six months of the year; the following year if peg ocurred during the last six months of the year. 
the crossing of a country-specific threshold - rather than an identical threshold across countries-for a stabilization to be selected. This rule is explained in Section II.

For each episode we collect seven years of data: the stabilization year, three years before, and three years after. The choice of this arbitrary 7-year window, particularly the three-year post-stabilization horizon, reflects the need to balance the objective of having a long enough horizon after the stabilization date and that of not having an horizon so long that inflation performance in the final year is largely unrelated to the stabilization program under analysis. The implication is that disinflations that last at least three years are classified as successful, but, in principle, there is no presumption that they will not fail later on. In practice, however, the classification of successful episodes would remain almost unchanged if we used a five-year post-stabilization horizon. ${ }^{5}$

When does an inflation stabilization fail? Any rule used to separate successes from failures is unavoidably arbitrary and so we consider three different measures to check the robustness of our results. These measures are described in the next section. At this stage, to provide a preliminary indication of the bivariate relationship between failed stabilizations and some of their potential determinants, we simply divide our sample into two groups. We consider that a stabilization has failed if, during the first three post-stabilization years $(T+1, T+2$, and $T+3)$, inflation exceeds $3 / 4$ of the inflation rate prevailing the year before stabilization $(T-1)$. This yields a group of 34 successful and 17 failed stabilizations (criterion 1 in Table 2). Figure 1 shows that there is a marked difference in inflation rates between the two groups already in year $T+1{ }^{6}$ Following a marked decline (of 50-60 percentage points) in year $T$ in both cases, inflation declines further (by some 15 percentage points) in the successful group, while it remains practically unchanged in the failing group. In years $T+2$ and $T+3$, the differences in inflation levels become more marked and statistically significant, confirming that this simple criterion of success separates the dataset in two groups with very different post-stabilization paths for inflation.

Why do so many initially successful disinflations fail over the following three years? Figures 2 and 3 suggest very clearly that insufficient policy adjustment, as captured by the post-stabilization path of monetary and fiscal variables, is partly responsible. Figure 2 shows that the path of credit growth is very similar to that of inflation.

\footnotetext{
${ }^{5}$ If a five-year horizon were used, the classification of 45 of the 51 episodes would remain the same. In one instance, a stabilization successful after three years fails during the following two; in the other five cases, stabilizations that fail on a three-year horizon succeed on a five-year horizon because another (successful) stabilization is initiated in the meantime. These results are based on criterion 1 described below.

${ }^{6}$ Figures 1 and 2 show the transformation, $\pi(1+\pi)$, rather than the actual level of the variable in order to prevent the width of the 95 percent confidence interval from obscuring the changes in the median. We use the same transformation in our regressions.
} 
$-6-$

Table 2. Successful Stabilization Episodes

\begin{tabular}{|c|c|c|c|c|}
\hline & & \multirow[b]{2}{*}{$\begin{array}{c}\text { Exchange rate } \\
\text { anchor }\end{array}$} & \multicolumn{2}{|c|}{ Successful } \\
\hline & & & Criterion 1 & Criterion 2 \\
\hline Argentina 1 & 1977 & & Yes & Yes \\
\hline Argentina 2 & 1980 & Yes & & \\
\hline Argentina 3 & 1986 & Yes & & \\
\hline Argentina 4 & 1991 & Yes & Yes & Yes \\
\hline Bangladesh & 1975 & & Yes & Yes \\
\hline Bolivia & 1986 & & Yes & Yes \\
\hline Brazil 1 & 1966 & Yes & Yes & Yes \\
\hline Brazil 2 & 1991 & & & Yes \\
\hline Chile 1 & 1965 & & Yes & Yes \\
\hline Chile 2 & 1975 & & Yes & Yes \\
\hline Congo, Democratic Republic of 1 & 1969 & & & Yes \\
\hline Congo, Democratic Republic of 2 & 1980 & & & \\
\hline Congo, Democratic Republic of 3 & 1985 & & & \\
\hline Costa Rica & 1983 & & Yes & Yes \\
\hline Dominican Republic & 1992 & & & Yes \\
\hline Ecuador 1 & 1990 & & & Yes \\
\hline Ecuador 2 & 1994 & Yes & & Yes \\
\hline Ghana 1 & 1978 & & & \\
\hline Ghana 2 & 1985 & & & \\
\hline Guinea & 1988 & & & Yes \\
\hline Guinea-Bissau 1 & 1990 & & & \\
\hline Guinea-Bissau 2 & 1993 & & & Yes \\
\hline Guyana & 1992 & & Yes & Yes \\
\hline Iceland 1 & 1976 & & & \\
\hline Iceland 2 & 1984 & Yes & & Yes \\
\hline Indonesia & 1967 & & & Yes \\
\hline Israel & 1986 & Yes & Yes & Yes \\
\hline Jamaica & 1993 & & & Yes \\
\hline Lebanon 1 & 1988 & & Yes & Yes \\
\hline Lebanon 2 & 1993 & & Yes & Yes \\
\hline Mexico 1 & 1984 & & & \\
\hline Mexico 2 & 1989 & Yes & & Yes \\
\hline Mozambique & 1988 & & Yes & Yes \\
\hline Nicaragua & 1991 & Yes & Ycs & Yes \\
\hline Nigeria & 1990 & & & \\
\hline Peru 1 & 1986 & Yes & & \\
\hline Peru 2 & 1991 & & Yes & Yes \\
\hline São Tom é \& Pr íncipe & 1992 & & & \\
\hline Sierra Leone 1 & 1988 & & & Yes \\
\hline Sierra Leone 2 & 1992 & & Yes & Yes \\
\hline Somalia 1 & 1982 & & & \\
\hline Somalia 2 & 1985 & & & \\
\hline Syrian Arab Republic & 1988 & & Yes & Yes \\
\hline Turkey & 1981 & & & Yes \\
\hline Uganda 1 & 1982 & & & \\
\hline Uganda 2 & 1989 & & Yes & Yes \\
\hline Uruguay 1 & 1969 & Yes & & Yes \\
\hline Uruguay 2 & 1976 & & & \\
\hline Uruguay 3 & 1981 & Yes & & \\
\hline Uruguay 4 & 1992 & Yes & Yes & Yes \\
\hline Zambia & 1994 & & Yes & Yes \\
\hline Total number of episodes & 51 & & 20 & 34 \\
\hline Successful programs in percent of total programs & & & (39) & $(67)$ \\
\hline Exchange rate-based stabilizations & & 13 & 5 & 9 \\
\hline Successful ERBS programs in percent of ERBS programs & & & (38) & (69) \\
\hline
\end{tabular}

Source: Hamann (2001). 
Figure 1. Inflation 1/

Temporary Stabilization

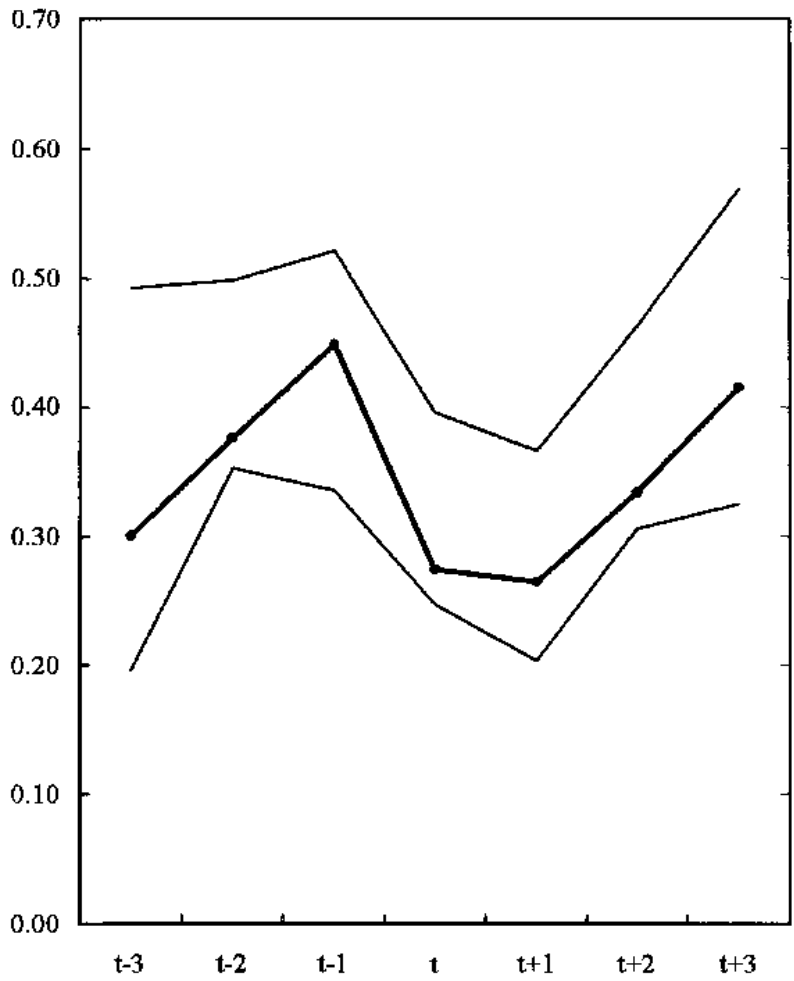

Durable Stabilization

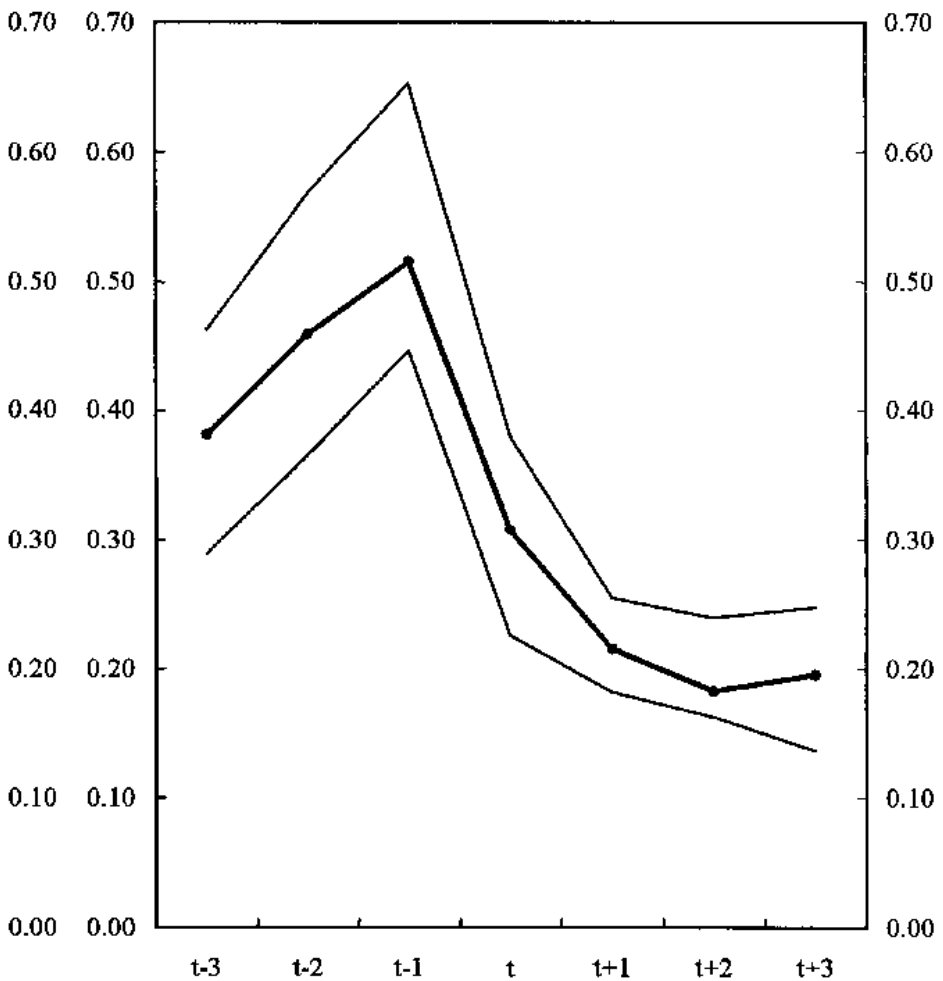

1/ Inflation (x) rescaled as $\pi=\mathrm{x} /(\mathbf{1}+\mathrm{x})$.

Source: IMF, International Financial Statistics, national sources and author's own estimates. 
Figure 2. Credit Growth

Temporary Stabilizations

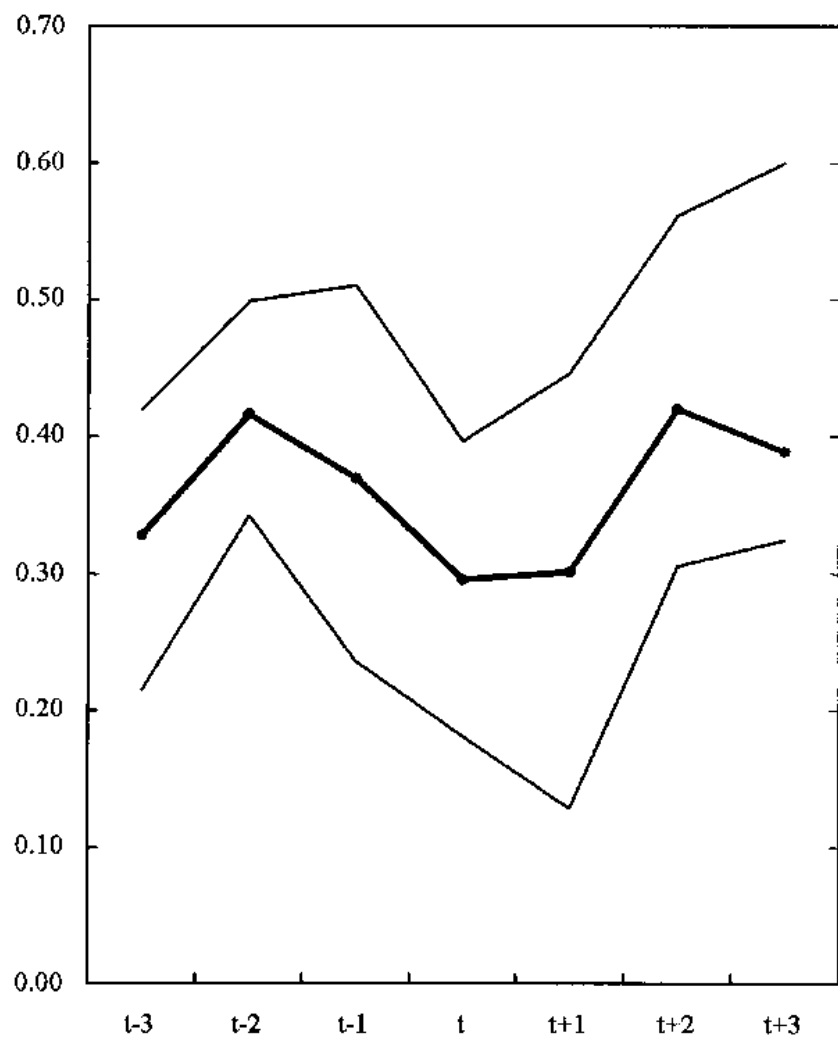

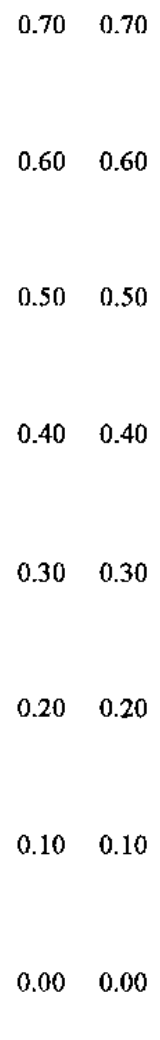

Durable Stabilizations

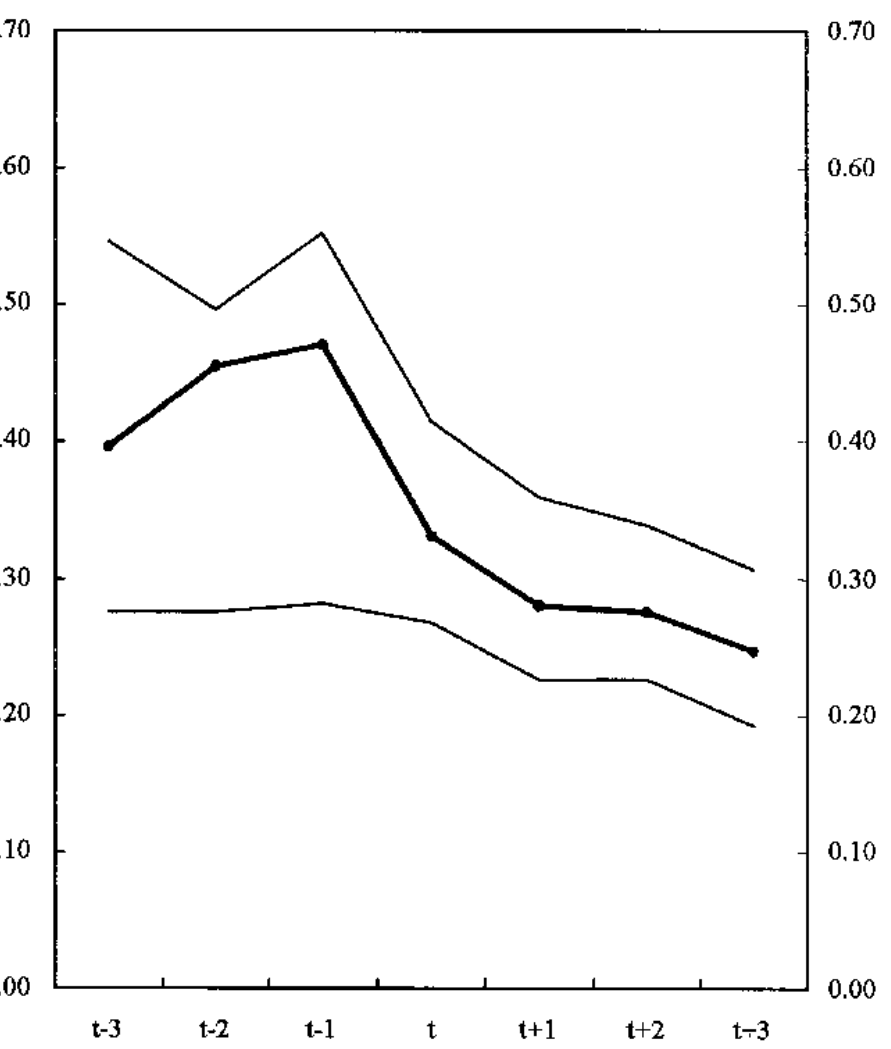

1/ Credit growth ( $x$ ) rescaled as $z=x /(1+x)$.

Source: IMF, International Financial Statistics ; national sources and author's own estimates. 
Figure 3. Fiscal Adjustment

(In percent of GDP)

Temporary Stabilizations:

Central Government Balance

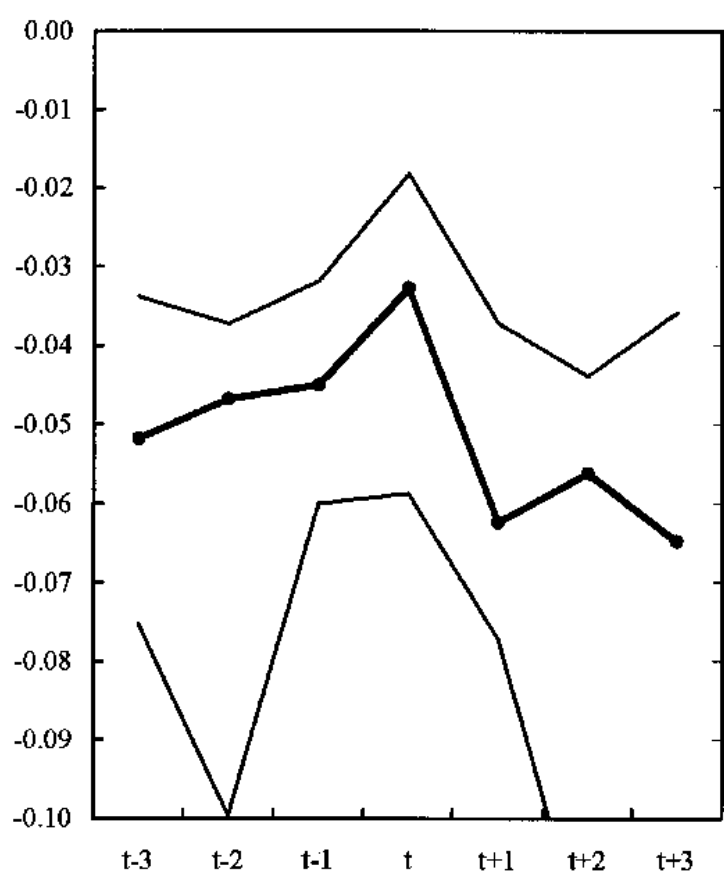

Temporary Stabilizations:

Deviations from Value in Year $t$

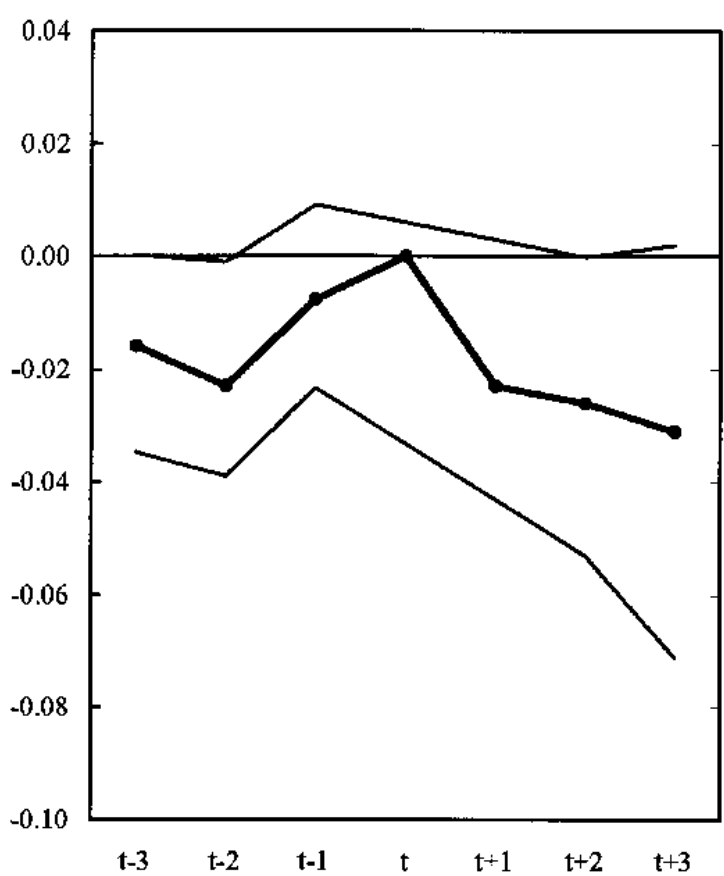

Durable Stabilizations:

Central Government Balance

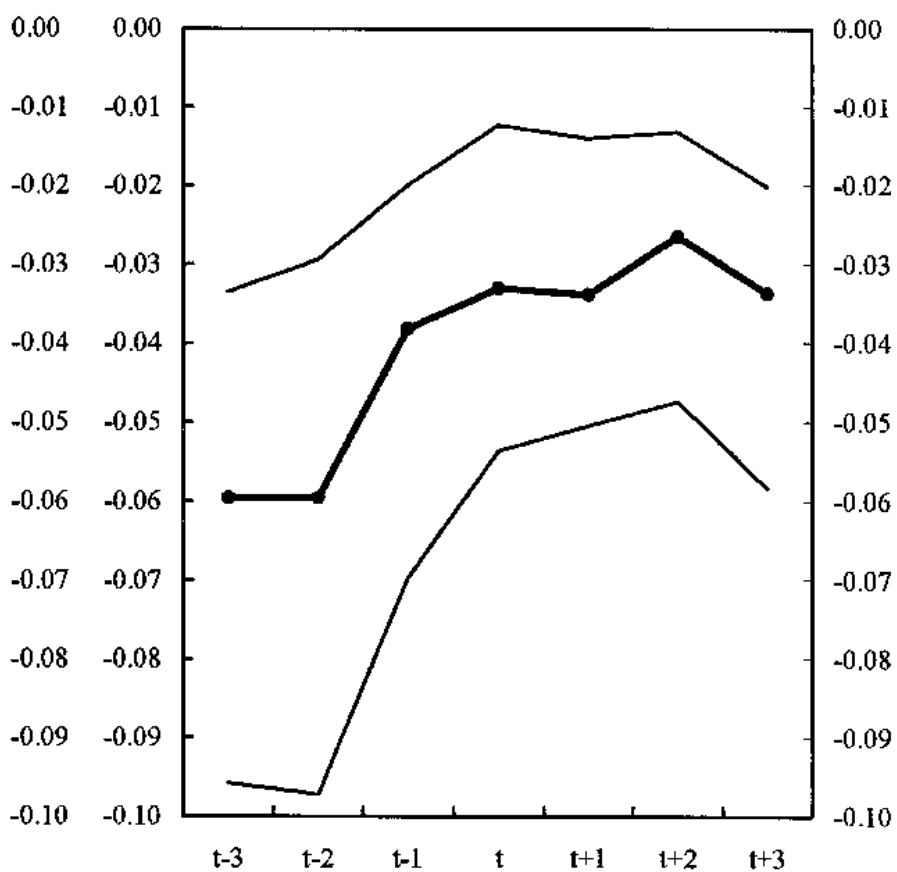

Durable Stabilizations:

Deviations from Value in Year $t$

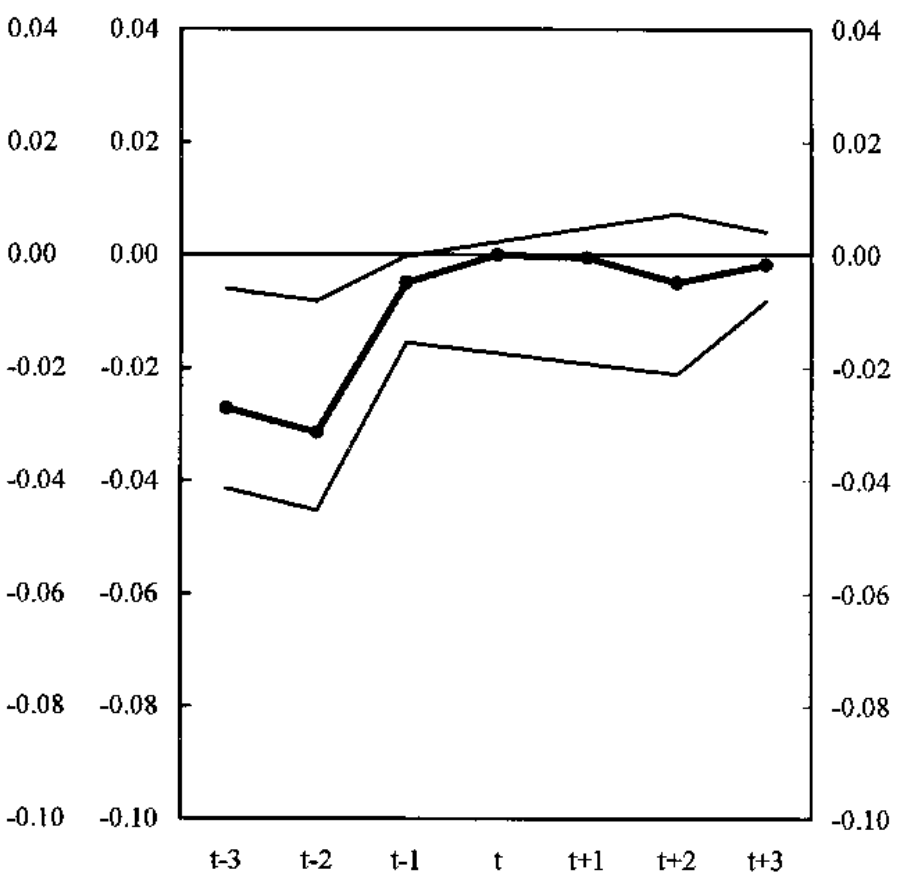

Sources: IMF, International Financial Statistics; national sources; and authors' own estimates. 
In the successful disinflations, there is a marked and durable decline beginning in year $T$. In the failed stabilizations, credit growth decelerates in $T$ but increases in $T+1$, and in $T+2$ reaches a higher level than in any pre-stabilization year. Figure 3 shows that, in year $T$, the fiscal deficits are nearly identical in both groups but they differ markedly in the following years. In failed stabilizations, all gains in fiscal adjustment obtained in the previous three years are lost in the first post-stabilization year. Fiscal adjustment is, instead, sustained in the successful group (the fiscal balance in year $T+3$ is almost identical to that in year $T$ ), while it continues to unravel in the failed-stabilization group (the fiscal balance in year $T+3$ is more than $2 \frac{1}{2}$ points of GDP worse than in year $T$.)

Should an analysis of the determinants of failed stabilizations end at this point, attributing the responsibility of failure entirely to the lack of fiscal and monetary adjustment? We do not believe that this would be appropriate for at least two reasons. First, even if monetary and fiscal policies could account fully for the degrees of success of the stabilization programs in our sample, this explanation could be considered of very little interest. Most likely, no inflation stabilization could succeed without some degree of fiscal and monetary adjustment. The key question is whether there are some identifiable factors that may be driving policy adjustment itself. Our empirical investigation focuses on these.

Second, it is also possible that monetary and fiscal policies may not be the only determinants of success or failure of inflation stabilizations. Other factors that shape economic agents' inflation expectations and actions are also likely to play an important role. As a result, given degrees of fiscal and monetary adjustment may result in success or failure. For this reason, in Section III we investigate other factors that, in conjunction with monetary and fiscal adjustment, may contribute to the failure of inflation stabilization.

In order to explore the empirical relevance of various potential determinants of success/failure of a stabilization plan, we address three main questions. First, we consider how important negative external shocks are as a determinant of stabilization failures. This question, which points to the importance of luck in the success of economic reforms, has received considerable attention in the empirical literature (Easterly, and others (1993)). External shocks are also featured as a key determinant of success in many theoretical models of stabilization (Dornbusch (1991)). Figure 4 shows that, indeed, in our sample, the growth rate of import demand from trading partners of countries with failed stabilizations dips in the first post-stabilization year whereas it increases for countries with successful stabilizations. In Section III, we find confirmation that this and other sources of external shocks, such as international interest rates and the terms of trade, contribute significantly to explain stabilization failures after controlling for other factors.

A second question we address in this paper is whether initial conditions matter. There is a body of theoretical literature, initiated by Drazen and Grilli (1993), predicting that "bad" initial conditions are conducive to a successful stabilization. Figure 1, indeed, shows that lasting stabilizations reach a higher pre-stabilization level of inflation than those that fail. In Section III, we test this and other dimensions of the "crisis hypothesis," and find strong 
Figure 4. Growth in Demand from Trade Partners

Temporary Stabilizations

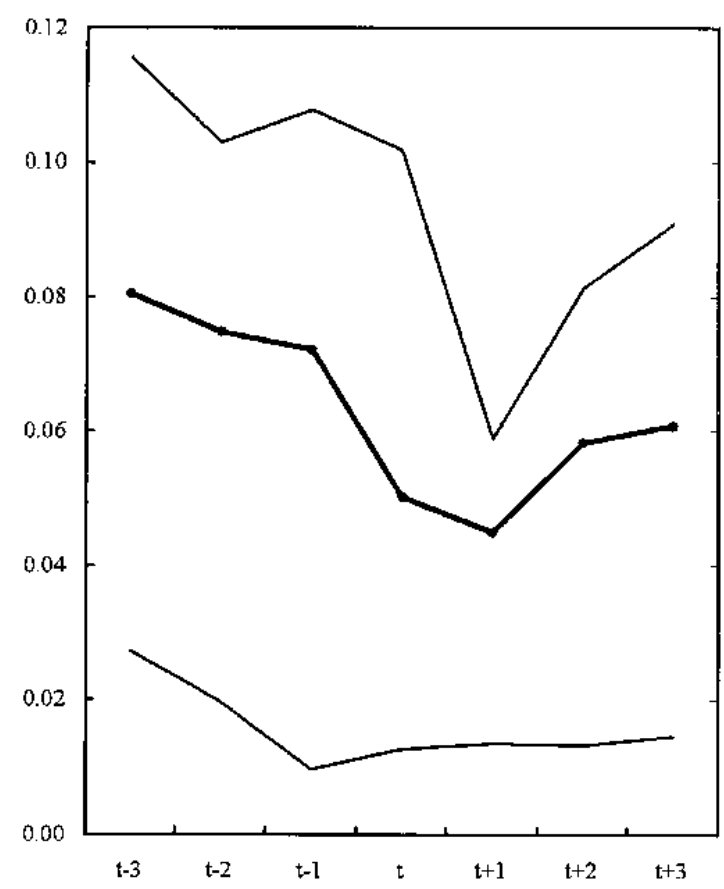

Durable Stabilizations

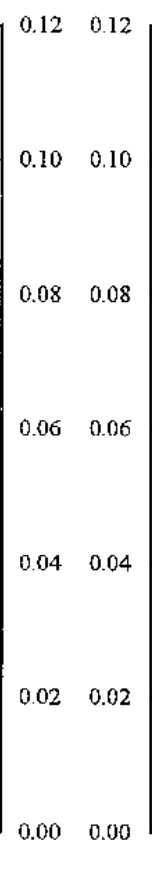

0.12

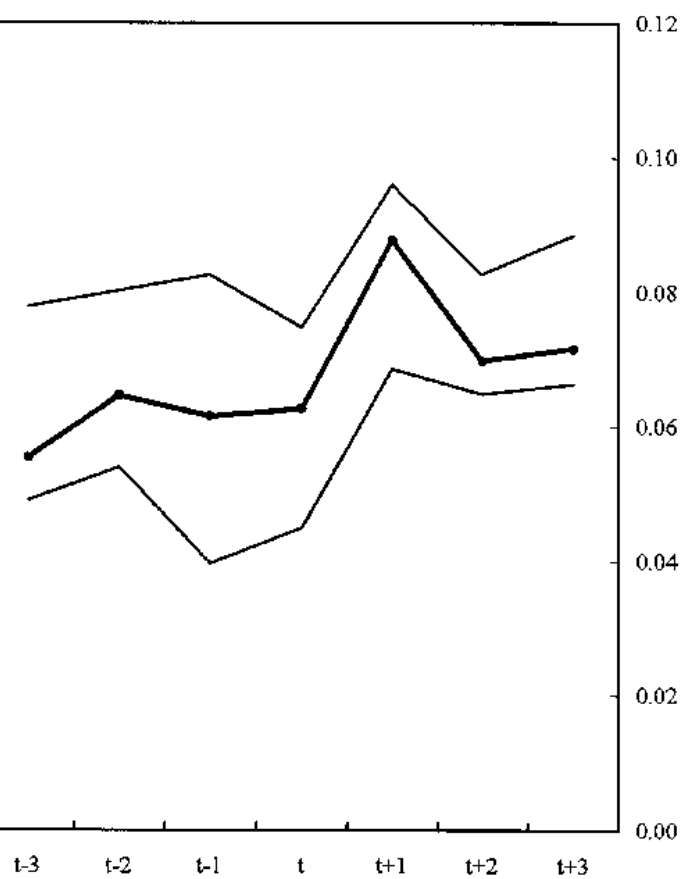

Source: IMF, World Economic Outlook; national sources and authors' own estimates. 
support for it. We also focus on two specific initial conditions that have important policy implications: the nominal anchor and the degree of openness of the economy. Interestingly, whereas a simple count of failed stabilizations reveals that ERBS failed as frequently as other stabilizations, no matter what criterion of success is used (Table 2), our multivariate econometric analysis shows that, after controlling for other possible determinants of failure, ERBS are more likely to succeed. We also test the relationship between initial openness (real and financial) and success. This issue has been studied by Romer (1993) and Lane (1997) who find that greater openness tends to be associated with lower inflation. We find only weak support for this hypothesis.

To assess the role of initial conditions, we also study whether inflation stabilization failures are state dependent, reflecting credibility and reputational factors. Economic theory has paid considerable attention to the role of reputation and credibility in inflation stabilizations, although the emphasis on reputation has declined in recent years. ${ }^{7}$ One dimension of state dependence relates to whether the probability of failure depends on having experienced long periods of high inflation prior to the beginning of the stabilization. Another dimension of state dependence has to do with whether, ceteris paribus, stabilizations that succeed (fail) in the initial years of our three-year window are more likely to succeed (fail) in the following years. Evidence in favor of these two forms of state dependence indicates that reputational factors play a role in inflation stabilization beyond that of adjustment policies, external shocks, and other initial conditions.

The third question we address is whether prevailing political conditions and institutions, contribute to explain the failure of inflation stabilizations. Many countries in the sample experienced major regime transitions towards or away from democracy prior to stabilization or during the three-year window we examine. Thus, we need to control for the potential effect of instability in the political regime on the likelihood of failure. A substantial body of literature has studied the relationship between inflation and political instability (Cukierman, Edwards, and Tabellini, 1992) and our result that short-lived political regimes are associated with a higher likelihood of failure can be interpreted along these lines. We also find that the probability of failure increases with a weak executive authority. The larger are the institutional constraints on the executive branch of government the more likely is an inflation stabilization to fail. In line with the prediction of reputational models of inflation (Barro, 1986) and political business cycle models (Nordhaus, 1975), we find that a new chief executive has a greater chance of success.

More recently, the political economy literature has focused on whether democracies with presidential (as opposed to parliamentarian) regimes and majoritarian (as opposed to proportional) electoral rules tend to be associated with smaller levels of government expenditure. Given the close link between fiscal imbalances and inflation, we investigate whether there is some evidence in our sample of a relationship between these political factors

${ }^{7}$ See Rogoff (1987) for a critical review of this literature through the mid 1980s. 
and the likelihood of stabilization failure, finding some support for the hypothesis that democracies with proportional electoral rules are more likely to fail. Finally, we find only some weak evidence that social conflict and lack of political cohesion are more likely to be associated with stabilization failures, as "war of attrition" theories à la Alesina and Drazen (1991) would suggest.

While the paper focuses on these three broad sets of questions, there are other questions on which it sheds some light. We find that inflation stabilizations from high levels generally do not entail a sacrifice ratio (in terms of foregone GDP growth), as found by Ball (1994) for industrial countries, a result that has also been documented by Harberger (1988), Gould (2001), and Hamann (2001). We also find that several measures of external shocks, initial conditions, and political factors retain their significance even after controlling for poststabilization macro variables, including fiscal and monetary policies.

The paper is organized as follows. Section II describes the scope of our investigation and our estimation strategy, including the solutions we propose to the several challengesranging from sample selection issues to potential endogeneity problems - associated with conducting an econometric analysis on our dataset. Section III presents the estimation results and relates them to the different hypotheses formulated in the theoretical literature. Section IV concludes and outlines some areas for future research.

\section{DATASET AND Estimation STRATEGY}

In this section, we describe the criteria used to select our sample and our proposed solutions to various econometric problems. These include: (i) the potential impact of the selection criteria on the estimation results; (ii) the choice of a specification search strategy that is adequate for a dataset with a small number of observations and a large number of potential explanatory variables; (iii) the selection of a measure of stabilization failure; (iv) the appropriate estimation technique; and $v$ ) how best to control for the potential endogeneity of some regressors.

\section{A. Identification of Episodes}

The selection of the stabilization episodes used in this study is based on the application of a set of rules to a data set of annual inflation rates for the period 1960-97 for a group of 143 countries. ${ }^{8}$ Hamann (2001) contains a detailed explanation of the procedure, as well as the pros and cons of using a rules-based selection criteria. Below, we provide a brief summary of his main findings in this regard.

\footnotetext{
${ }^{8}$ This represents a subset of countries for which the IMF publishes data, which excludes Eastern European countries and the former republics of the Soviet Union.
} 
Building upon earlier work by Bruno and Easterly (1995), Easterly (1996) defines a stabilization episode as a movement from an "inflation crisis" to a "noncrisis" period where the former is defined as a period of at least two consecutive years of inflation above 40 percent and the latter as a period of at least two consecutive years with inflation below 40 percent. The two-year minimum is used to eliminate spikes in inflation due purely to onetime price shocks such as changes in key import prices, devaluations or price liberalizations; the 40 percent threshold level is found by Bruno and Easterly (1995) to be useful in discriminating between periods of very high inflation and moderate to low inflation. To establish the timing of stabilizations, Easterly defines the peak year during the crisis period as "year 0", or the stabilization year, and the year after the peak as the first post-stabilization year.

Easterly found 28 stabilization episodes (Table 3 ), and his rule could be considered a relatively stringent criterion for the selection of stabilization episodes. Notably, the list excludes a number of well documented, albeit mostly failed, stabilization attempts, including the Argentinean and Chilean tablitas of the late 1970s, and the heterodox programs of Argentina, Brazil and Peru in the mid-1980s. Easterly's sample also excludes several programs in Africa.

After experimenting with several numerical rules, Hamann (2001) reports the results obtained with three of them, all based on the requirement that, prior to stabilization, inflation remained at or above 40 percent for at least two consecutive years. In that study, the author opted for selecting a sample produced by a rule that did not impose a uniform ceiling on post stabilization inflation but required a reduction of at least $1 / 4$ in inflation in the first year of stabilization (followed by the requirement that inflation remained below the pre-stabilization level for another year). This exercise produced 51 stabilization episodes, including all 28 found by Easterly (although 17 of them are dated a year later). This criterion also picked up the well-known episodes not captured by Easterly's rule.

\section{B. Sample Selection and Scope of Our Study}

An episode-selection strategy based exclusively on the actual behavior of inflation implies that the selected stabilization episodes are those for which a given reduction in inflation is actually observed. The resulting sample is, thus, comprised of programs that enjoyed some minimum degree of success. Short-lived programs that did not manage to make a significant dent to average annual inflation were not picked up. ${ }^{9}$ This incidental truncation would lead to a sample selection bias if we used our sample to draw inferences on the entire set of possible inflation stabilization attempts - because some bona fide stabilization episodes may have been left out. Thus, we limit the scope of our study to the class of inflation stabilizations that satisfy minimum qualifying criteria and our inferences on what makes stabilizations fail are then valid only within this class.

\footnotetext{
${ }^{9}$ The rules may also be picking up the delayed effects of programs that pursued more than one objective at a time or, more likely, programs that pursued a sequence of events, such as restoration of external balance first, and only subsequently a reduction in inflation. Thus, either by focusing only on relatively successful episodes, or by pushing forward the timing of stabilization, it is likely that our sample of episodes may be associated with a relatively positive economic outlook around stabilization time (i.e., higher growth, better external accounts, etc.).
} 
Table 3. Stabilization Episodes: Nominal Anchors

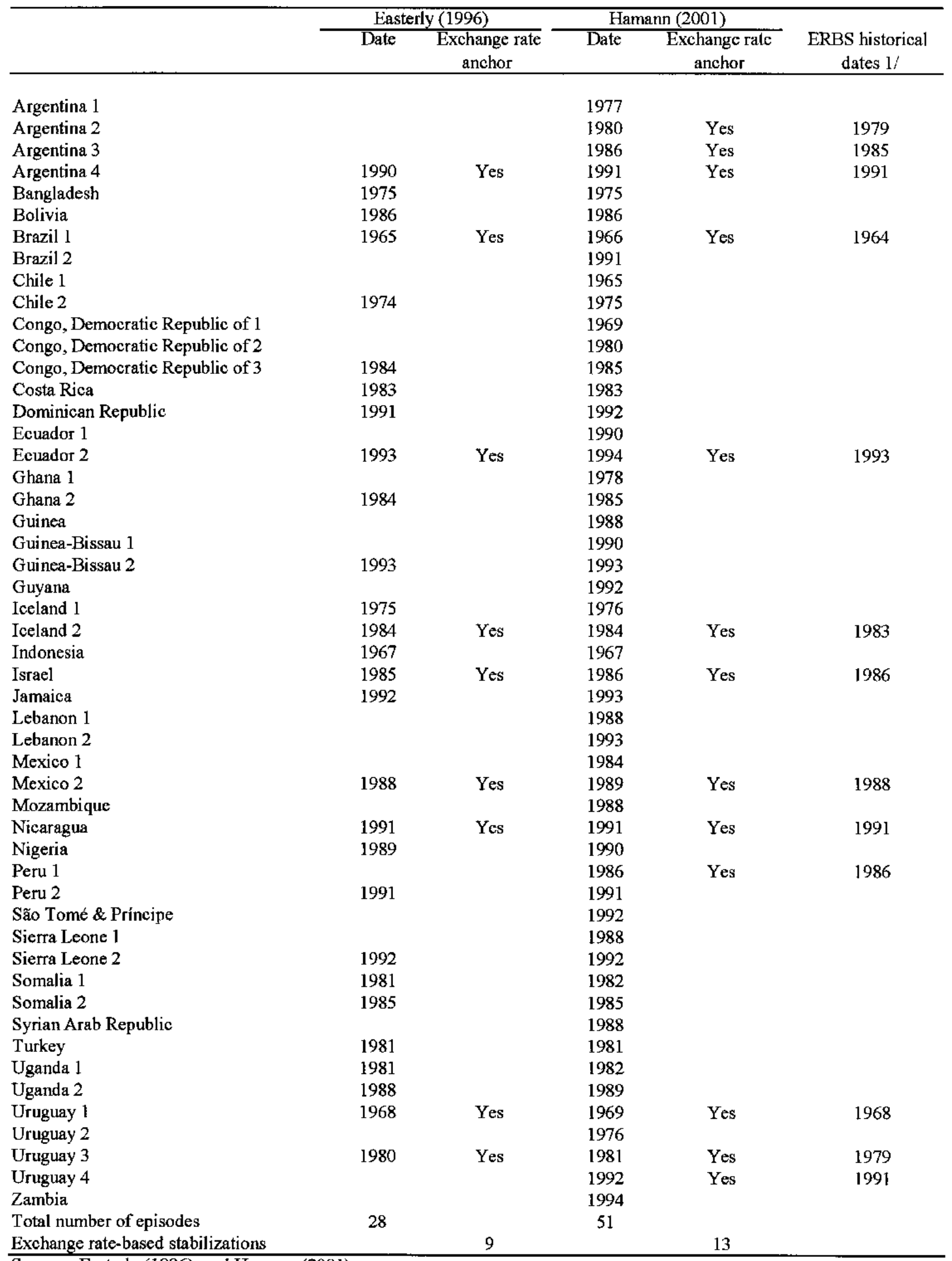

Sources: Easterly (1996), and Hamann (2001).

1/ Year in which exchange rates were actually pegged, if peg ocurred within the first six months of the year; the following year if peg ocurred during the last six months of the year. 
For example, if we were to find that larger fiscal surpluses are associated with disinflations that last at least three years, we could make a valid inference on the extent to which post-stabilization fiscal adjustment is conducive to a lasting stabilization within the set of high-inflation stabilization attempts that are initially successful. We could not extend this conclusion to the set of all attempts at stabilizing high inflations because of the potential bias associated with the incidental truncation. ${ }^{10}$

We conduct, however, a robustness check on the implications of our sample selection criterion. To have an idea of whether other criteria would have yielded different results, we estimate our benchmark econometric specification also on the smaller sample of 28 episodes identified by Easterly (1996). ${ }^{11}$ The results obtained using this smaller sample are broadly consistent with the key results obtained with our sample.

\section{Specification Search}

The small number of observations and the large number of potential explanatory variables in our dataset make a general-to-specific specification search impossible. To address this issue, we adopt the following strategy. We organize our dataset of 51 inflation stabilization episodes as a panel dataset. The 51 episodes represent the cross-section dimension of the panel; the three post-stabilization years $(T+1, T+2, T+3)$ constitute the time-series dimension. ${ }^{12}$ This panel structure-with the time-series dimension defined in relation to a cross-section-specific reference date (the stabilization year, in our case) - was pioneered by Fama, and others (1969) in their classical study of stock splits. Recent studies that have performed econometric estimates on panel datasets with the same format include Bertocchi and Canova (1996) and Milesi-Ferretti and Razin (1998). We thus estimate our empirical models on a panel dataset with 153 observations. ${ }^{13}$ We also use graphical analysis to guide us in the identification of potential regressors.

${ }^{10}$ In practice, this bias would arise only if the errors of the equation measuring the determinants of successful inflation stabilizations were correlated with the errors of an equation modeling the determinants of the selection of a stabilization episode. This issue is discussed in greater detail below, where an analogous problem arises in relation to the use of a nominal anchor variable as a regressor.

${ }^{11}$ When stabilization dates do not coincide, we use ours.

${ }^{12}$ We also use $T$ and $T-j(j=1,2,3)$ data to control for initial conditions.

${ }^{13}$ The total number of observations used in the econometric estimates is 150 or 153 depending on whether the government fiscal balance-which is not available for Indonesia in the $1960 \mathrm{~s}-$-is among the regressors. 
We perform the specification search in stages by gradually adding blocks of explanatory variables and excluding at each stage those regressors that, as a result of the addition of new variables, become statistically insignificant. We start by using only: (i) initial conditions, such as the levels - in the years prior to the stabilization - of macro and policy variables, including a variable measuring the number of pre-stabilization years with inflation above 40 percent and dummy variables for the openness of the current account and the capital account (based on the IMF's classification) at the time of the stabilization; (ii) variables controlling for external conditions (terms of trade, U.S. interest rates, growth of import demand from trading partners); and iii) a dummy variable for the nominal anchor taking value 1 in ERBS, controlling for its potential endogeneity with the methodology described below.

We then add to the best specification from this first stage a set of political economy variables - such as features of the political systems, including their durability, the degree of democracy, and, within the subset of democratic regimes, whether they are parliamentarian or presidential and whether the electoral system is proportional or majoritarian; the numbers of years in office of the chief executive; the degree of political and social fragmentationand obtain a second specification. In a third stage we add groups of variables dated $T, T+1$, and $T+2$, starting with nonpolicy macro variables (GDP growth rates, output gaps, international reserves) and ending with government fiscal balances and domestic credit growth. The logic of this sequential search is not only to estimate models with a reasonable total number of potential regressors but also to include only exogenous variables at the beginning and add the variables that are more at risk of being endogenous at the end. This allows us to interpret the results based on a smaller set of explanatory variables as a reduced form of a more complicated structural model with simultaneous equations. Note that, to eliminate obvious sources of endogeneity, we lag all post-stabilization variables one period. Nevertheless, as discussed below, some variables may still be endogenous because of an omitted variable bias.

\section{Measuring Failure}

The dependent variable in our benchmark estimates is a zero-one stabilization failure dummy taking on a value of one when a stabilization fails and zero when it does not. Specifically, this binary variable $\left(F A L 1_{T+i} ; i=1,2,3\right)$ takes value zero when inflation in year $T+i$ is lower than 75 percent of inflation in year $T-1$ and one otherwise. The panel structure of the data implies that, if the requirement for failure is only temporarily satisfied, the same stabilization episode may be classified as a failure in year $T+1$ and as a success in year $T+2$ and $T+3$.

To verify the robustness of our results, we use two additional measures of failure. The first is another dummy $\left(F A I L 2_{T+i}\right)$ taking on a value of zero if inflation in year $T+i$ is lower than inflation in year $T$ and one otherwise. Since this amounts to a stricter criterion of success, there are more stabilization failures with FAIL2 than with FAIL1 (20 successful and 
31 failed stabilizations, as shown under column 2 in table 2). The second alternative measure of durability is a continuous variable equal to the ratio of inflation in year $T+i(\mathrm{i}=1,2,3)$ to inflation in year $T\left(R A T I O_{T+i}=\pi_{T+i} / \pi_{T}\right)$. ${ }^{14}$ High values of this ratio will then be associated with stabilization failures.

Both continuous and binary variables have pros and cons. The continuous variable allows a more precise measure of inflation reductions but can take extreme values that could affect estimation results. This problem can be particularly serious in cases of extremely high inflation. The binary variables are more robust to outliers but are more imprecise: two very similar inflation outcomes may have a different binary classification if they are just on opposite sides of the selected threshold level. Estimating models with both continuous and binary dependent variables allows us to check whether the unavoidable shortcomings of each type of dependent variable affect our results in a significant manner.

\section{E. Estimation Techniques}

To be able to draw conclusions on the determinants of stabilization failure within our sample, we need to address the econometric issues associated with the binary nature of $F A I L I$ and FAIL2, the panel structure of the data, and our interest in assessing in-sample state dependence. We take the binary nature of $F A I L I$ and $F A I L 2$ into account by estimating a probit model. The panel structure of the data creates the potential problem of episode-specific effects, which-if ignored-might bias the estimated coefficients. The presence of several time-invariant variables and the short time-series dimension of our dataset precludes, however, the estimation of fixed-effects models. Our benchmark regression is then a pooled regression with $F A L L 1$, in which data from different episodes are pooled together sharing a common intercept term. We take, however, into account the panel structure of the data by allowing for heteroskedastic errors across episodes. Allowing for heteroskedasticity across countries or calendar years yields very similar results.

To allow for in-sample state dependence, we include in our benchmark specification lagged values of the dependent variable in periods $T+2$ and $T+3$. In the probit regressions, the lagged value of the dependent variable in period $T+1$ is zero because stabilization in year $T$ is by definition always successful. This amounts to assuming that the outcome in period $T+1$ is determined only by the other explanatory variables and that state dependence is meaningful only from period $T+2$ onwards. This is not an unusual way of dealing with the problem of initial conditions typical of dynamic probits (see, for example, Heckman, 1981).

14 The inflation measure $\pi_{T+i}$ actually corresponds to the transformation $\pi_{T+1} /\left(1+\pi_{T+i}\right)$ where $\pi_{T+i}$ is the actual inflation rate in year $T+i$. We apply this common transformation to limit the heteroskedasticity problems that hyperinflation relapses otherwise cause and the impact of outliers. 
Moreover, this is justified because our sample begins at $T+I$ not by chance but by construction, as we are interested in the evolution of inflation only in the post-stabilization years. Our treatment of the lagged dependent variable is similar when it is continuous ( $R A T I O)$. In this case, the lagged dependent variable at $T+l$ should in principle be one. However, we set it to zero so that the regression will try to explain $R A T I O_{T+1}$ only with the other explanatory variables; the lagged dependent variable $R A T I O_{T+j-1}$ would then be allowed to explain $R A T I O_{T+i}$ only for $i=2,3 .^{15}$

Since the estimates of our pooled regression might be biased in the presence of unobservable heterogeneity across episodes, we also estimate random effects models for FAIL1, FAIL2, and RATIO. Controlling for potential unobservable heterogeneity across episodes is particularly important in view of our interest in identifying in-sample state dependence. By neglecting possible episode-specific effects, we would risk confusing spurious state dependence due to temporally persistent unobservables with true state dependence, namely a genuinely different behavior of inflation after a stabilization has failed or succeeded in early years. A random effects estimator for the simple form of dynamic probit we consider is consistent even in the case where only the number of cross-sections tends to infinity (Hsiao, 1986 , p. 170).

However, if the episode-specific effects are correlated with the other regressors, the random effects estimator would be characterized by an omitted variable bias. Since the absence of consistent fixed-effects estimates precludes us from computing the Hausman test to verify the existence of a significant correlation between the regressors and the episodespecific effects, we present the pooled regressions as a norm accompanied by the random effects estimates only when the proportion $\rho$ of the variance contributed by the episodespecific variance component is statistically different from zero. ${ }^{16}$ In all probit estimates with FAIL1 and FAIL2, the null hypothesis of $\rho$ equal to zero was accepted. When rejected, as it happened with the continuous measure $R A T I O$, the results of the pooled and random effects regressions were nonetheless similar. This is not a surprising result if one considers that our dependent variable, and many of the regressors, are measured relative to their episodespecific value in period $T$.

${ }^{15}$ This anomalous feature of our model, together with the fact that several explanatory variables in our specification are time-invariant, prevents us from estimating a dynamic regression for RATIO with the Anderson and Hsiao (1981) instrumental variable estimator or Arellano and Bond (1991) GMM estimator. Both methods, in fact, require differencing the estimated equation and use past lags of differenced and nondifferenced variables as instruments.

${ }^{16}$ This was done using the likelihood ratio test for FAILI and FAIL2 and the Breusch-Pagan Lagrange multiplier test for $R A T I O$. We report the results of these tests for each specification in our tables. 
We also report static estimates that ignore the possibility of state dependence for our benchmark regression with FAILI (results were similar in static regressions with FAIL2 and $R A T T O$ ), to assess whether the inclusion of lagged dependent variables critically affects the other coefficients. We also estimated a static random effects model with serial correlation of the errors, that-when the estimation converged-yielded similar results (for reasons of space these results are not shown but are available from the authors upon request).

\section{F. Endogeneity Issues}

There is a risk that an omitted variable bias might affect the estimates of the coefficients measuring how the nominal anchor and fiscal and monetary adjustment contribute to stabilization failure. This bias may emerge if two conditions are simultaneously satisfied: (i) the durability of stabilization depends not only on observable government policies but also on the unobservable "ability" of the government to stabilize; and (ii) this unobservable "ability" to stabilize also affects the choice of the anchor or the degree of monetary and fiscal adjustment. For example, a government with a "tough" anti-inflation reputation is likely to be more successful than a government with a "weak" reputation for any degree of monetary and fiscal adjustment, and for any nominal anchor, not only because of its stronger "anti-inflation credentials," but also because of its ability to implement other policies, like incomes policies and structural reform policies (which may contribute to make a stabilization successful but are not explicitly controlled for in our regression). If this "tough" government is also more likely to choose an exchange rate anchor and implement a larger monetary and fiscal adjustment than a "weak" government, estimation techniques that neglect this correlation will tend to overestimate the effect of these policies (i.e., fiscal and monetary adjustment and the anchor).

This potential omitted variable bias is not only of interest to the econometrician but is also of critical importance for the policymaker. If there is an omitted variable bias, standard estimation techniques (e.g., OLS) may indicate that, to disinflate successfully, a government only needs to choose an exchange rate anchor and adopt moderately restrictive monetary and fiscal policies, when in practice its initial reputation and the adoption of incomes and structural policies are equally essential and could be replaced only by much larger fiscal and monetary adjustments.

The empirical labor economics literature has faced very similar problems in estimating the effects of schooling on wages. ${ }^{17}$ To the extent that the unobservable "ability" of an individual affects both his school attendance and his wages, wage equations that neglect this correlation would overestimate the returns to schooling. To address this

${ }^{17}$ Gould (2001) first drew an analogy between the labor literature and that on inflation stabilization programs as a way to address the possible endogeneity of the anchor. 
problem, the labor literature has developed specific estimation techniques. When the schooling measure is continuous - as, in our case, the measures of monetary and fiscal adjustment are-standard instrumental variable techniques are appropriate. When the schooling measure is dichotomous--as, in our case, the exchange rate anchor dummy is-a two-step procedure devised by Heckman (1979) or a bivariate probit are the appropriate estimation techniques depending on whether the variable measuring the returns is continuous ( $R A T I O$ in our case) or dichotomous (FAIL1 and FAIL2 in our case). ${ }^{18}$ In the rest of this section, we briefly describe how we use these procedures to correct for the possible endogeneity of the exchange rate anchor. The problems associated with finding an appropriate instrument for the monetary and fiscal adjustment variables-i.e., a variable that affects the marginal cost of monetary and fiscal adjustment but is uncorrelated with the government's ability to adjust and, at the same time, does not contribute directly to the durability of stabilization - prevent us, for the moment, from performing an instrumental variable estimation to address the endogeneity problem of these variables. ${ }^{19}$

When one of the stabilization failure dummies (FAIL1 and FAIL2) is used to measure durability, we take into account the possible endogeneity of the exchange rate anchor dummy (ANCHOR) by estimating a bivariate probit of the following form:

$$
\begin{array}{cc}
\text { ANCHOR }=\beta_{1} x_{1}+u_{1} & , \quad \operatorname{Var}\left(u_{1}\right)=1 \\
\text { FAILI }_{i}=\beta_{2} x_{2}+\gamma_{1} \text { ANCHOR }+u_{2} & , \operatorname{Var}\left(u_{2}\right)=1, \quad i=1,2
\end{array}
$$

where $x_{1}$ and $x_{2}$ are vectors of exogenous variables.

When appropriately identified, this bivariate probit yields an estimate of the covariance between the errors of the two equations $\left(\operatorname{Cov}\left(u_{1}, u_{2}\right)=\delta\right)$. If this covariance is significantly different from zero, a univariate probit estimation of equation (1) would yield a biased estimate of the coefficient $\gamma_{1}$ measuring the contribution of the anchor to the success of the stabilization. The correlation between the errors of the two equations would be different from zero if, for example, the unobservable ability of the government to stabilize affected both the choice of the anchor and the success of the stabilization.

\footnotetext{
${ }^{18}$ These estimation techniques to control for potential endogeneity problems can be easily used in combination with dynamic probits but not with duration models. This is one of the reasons why we use the first class of models to study why inflation stabilization may fail. A more fundamental reason is that we are more interested in what makes initially successful stabilizations fail (i.e., what causes a transition from success to failure) than in what determines the duration of a low inflation spell. The two classes of models are, however, closely related (see, for example, Amemiya, 1985, pp. 421-28).

${ }^{19}$ This problem does not have any straightforward solution in the labor economics literature either (see Card, 2001, for a recent survey.)
} 
Before estimating the bivariate probit, it is important to note that, if $u_{1}$ and $u_{2}$ are not independent, the simultaneous equation model (1)-(2) is not fully recursive and at least one of the exogenous variables on the right-hand-side of the exchange rate anchor equation (1) should be excluded from the list of regressors in equation (2) to ensure its identification. ${ }^{20}$ In our estimates, we identify the model by including in $x_{l}$ a dummy variable taking on a value of one in all stabilization episodes involving African or Middle-Eastern countries (which in our sample tended not to choose an exchange rate anchor) and zero otherwise. This regional dummy appears to be unrelated to the probability of a successful stabilization and, thus, a valid instrument. ${ }^{21}$ For each univariate specification (2), we then always estimate also a bivariate probit model (1)-(2) ${ }^{22}$ We always report the coefficient estimates of the univariate specification (2), while we report the bivariate estimates only when the correlation coefficient between the errors of the two equations is significantly different from zero.

When the continuous variable $R A T I O$ is used to measure durability, we account for the possible endogeneity of the exchange rate anchor dummy ( $A N C H O R$ ) by estimating a mixed structure:

$$
\begin{gathered}
A N C H O R=\beta_{1} x_{1}+u_{1} \quad, \quad \operatorname{Var}\left(u_{1}\right)=1 \\
\text { RATIO }=\beta_{2} x_{2}+\gamma_{1} \text { ANCHOR }+u_{2}
\end{gathered}
$$

where $x_{l}$ and $x_{2}$ are vectors of exogenous variables.

The key difference from the system (1)-(2) is that, while $A N C H O R$ is still a dichotomous variable, $R A T I O$ is a continuous variable. As a result, the assumption $\operatorname{Var}\left(u_{1}\right)=1$ (typical of probit estimation) is sufficient to ensure the identification of this system and the two sets of regressors $x_{1}$ and $x_{2}$ may include the same variables. ${ }^{23}$ The model is then always identified and we can estimate $\operatorname{Cov}\left(u_{1}, u_{2}\right)=\delta$ to test the possible presence of an omitted variable bias. Another difference from model 1-2 is that in this case the estimation method

${ }^{20}$ Maddala (1983, pp.122-24).

${ }^{21}$ The percentage of successful stabilizations in African or Middle-Eastern countries is 60 percent according to criterion $I$ and 40 percent according to criterion 2 in Table 2, while the corresponding figures for the entire sample are 67 percent and 39 percent.

${ }^{22}$ Because of the complexity of this estimation technique, we estimate a bivariate model only for the pooled regression with heteroskedastic errors and not for the random effects model.

${ }^{23}$ Maddala (1983, pp.120-22). 
can be either maximum likelihood or an equivalent two-step estimator, analogous to that devised by Heckman (1979) for sample selection problems. ${ }^{24}$ As in the previous case, we always report univariate coefficient estimates of equation (4), whereas we report those from the Heckman's procedure only when the correlation coefficient between the errors of the two equations is significantly different from zero.

\section{RESUlts}

In this section we illustrate the results obtained from applying the estimation strategy and techniques described in the previous section to our dataset. When explaining the results, we draw on the relevant strand of the theoretical literature on inflation stabilization. We start by presenting our benchmark estimates for FAIL1. We then check the robustness of the main results to the definition of failure by presenting estimates for FAIL2 and RATIO. Finally, we show the results obtained by estimating a similar set of regressions on Easterly's (1996) sample.

\section{A. Benchmark Estimates}

Tables 4 and 5 summarize the main results and illustrate the steps of the specification search for FAIL1. The estimates in Table 4 correspond to a dynamic probit specification. As a norm we present the univariate pooled estimates. We present the maximum likelihood bivariate probit estimates when the Wald test rejects the null hypothesis of no correlation between the errors of equations (1) and (2). The bivariate estimates are, however, very similar to the univariate estimates. We also estimate a random effects model for the univariate specification but, given that the likelihood ratio test never rejects the null hypothesis of zero contribution of the episode-specific variance component, we do not present the results of this estimation technique for FAIL1. We follow the same approach for all full-sample results presented in this paper. Table 5 presents the results for a static regression that excludes lagged values of FAIL1, thus neglecting possible in-sample state dependence. ${ }^{25}$

${ }^{24}$ Greene (2000, pp. 933-34).

${ }^{25}$ As mentioned earlier, we also estimated a static random effects model with AR(1) serial correlation. When the estimated coefficient vector converged the results were always confirmed, but we could not get convergence for some of the larger models in column (3). 
$-24-$

Table 4. Dynamic FAILI Estimates

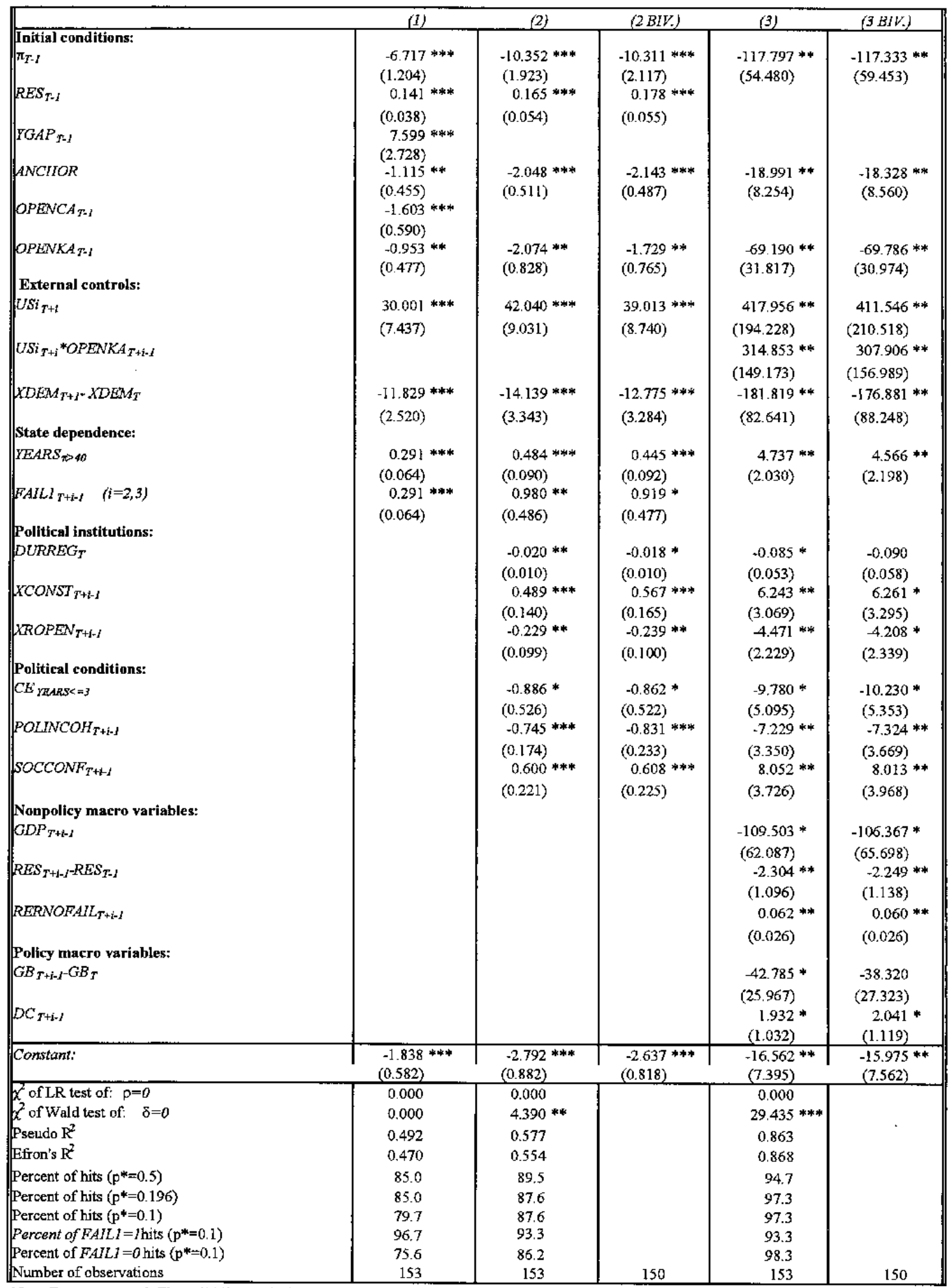

Note: Data are annual. Three $\left({ }^{* * *}\right)$, two $(* *)$, and one $\left({ }^{*}\right)$ asterisks mark stalistical significance at respectively one, five, and ten percent levels. 
Table 5. Static FAILI Estimatcs

(Heteroskedastic corrected standard errors in parenthesis)

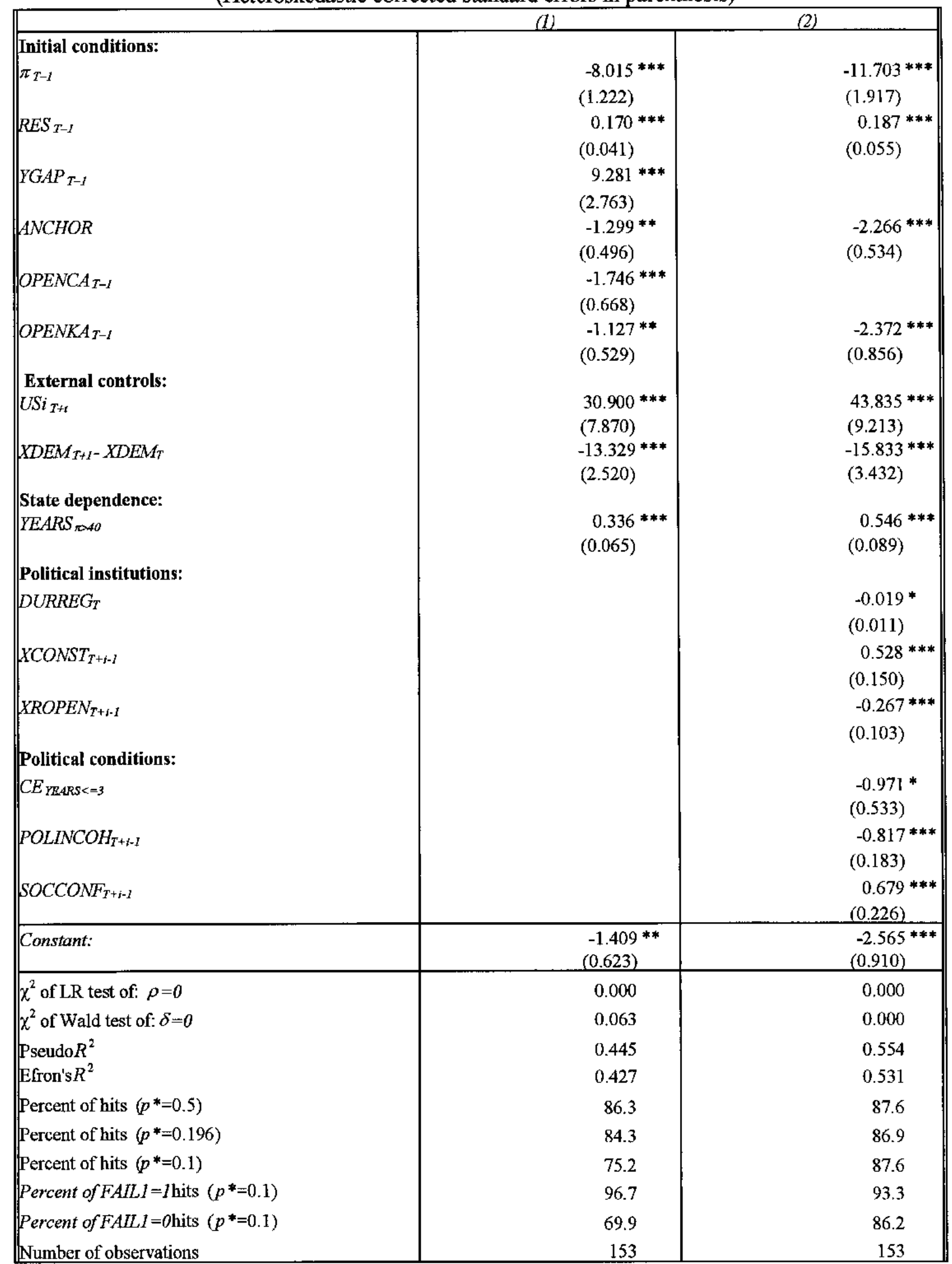

Note: Data are annual. Three $\left({ }^{* * *}\right)$, two $\left({ }^{* *}\right)$, and one $\left({ }^{*}\right)$ asterirsks mark statistical significance at respectively 1,5 , and 10 percent levels. 
In this case, the Wald test never rejects the null hypothesis of no correlation between the errors of equations (1) and (2). ${ }^{26}$

Column (1) in each table presents the coefficient estimates for a model with only external controls and initial conditions, including the nominal $A N C H O R$ and measures of state dependence. Column (2) shows the results for a model that also includes measures of political institutions and conditions. Column (3) adds post-stabilization nonpolicy and policy macro variables, including measures of fiscal and monetary adjustment. At each step, we add a new set of variables and we drop the variables of previous models that are no longer statistically significant.

The significance of each block of variables in Table 4 provides some preliminary indications on the determinants of stabilization failures. A striking feature is the very good fit of the model with only external controls and initial conditions. The pseudo- $R^{2}$ of this model is 0.492 (column (1)) ${ }^{27}$ Adding political economy variables increases the fit to 0.577 (column (2)). Finally, adding nonpolicy and policy adjustment variables increases the fit to 0.863 (column (3)). As the pseudo- $R^{2}$ cannot be interpreted as the share of the variance of the dichotomous variable explained by the regression, ${ }^{28}$ we also present other measures of goodness of fit. Efron's (1978) $R^{2}$ confirms the results obtained with the pseudo- $R^{2}$. All specifications in Table 4 predict correctly at least 85 percent of the stabilization outcomes when we use a probability threshold, $p^{*}$, of 0.5 to predict failure. As the threshold of 0.5 may not be appropriate in the case of our unbalanced sample with more successes than failures (Greene, 2000, pp. 833-34), we also present the percentage of stabilization outcomes correctly predicted with a lower threshold equal to the sample frequency of failure in the 153-observations panel $\left(p^{*}=0.196\right)$, which confirms the good performance of the estimated model. Finally, we show the effect of lowering $p^{*}$ to 0.1 with the objective of minimizing the error in predicting failures. With this low threshold, all specifications predict correctly more

${ }^{26}$ Given that column (3) in Table 4 already corresponds to a static probit because lagged values of FAILI are no longer significant when we add adjustment variables to the dynamic specification, we do not repeat column (3) of Table 4 in Table 5.

${ }^{27}$ Note that this successful fit is only in minimal part due to the inclusion of the lagged dependent variable among the regressors: a static pooled regression with the same set of explanatory variables has a pseudo- $R^{2}$ of 0.445 (Table 5).

${ }^{28}$ The pseudo- $R^{2}$ is McFadden's (1974) likelihood ratio index equal to $1-\ln L / \ln L_{0}$, where $\ln L$ is the value of the log-likelihood function of the model at a minimum and $\ln \mathrm{L}_{0}$ is the $\log$ likelihood computed with only a constant term. This measure is bounded by zero and one. Efron's (1978) $R^{2}$ is equal to $1-\Sigma(F A I L 1-p)^{2} / \Sigma(F A I L 1-p)^{2}$, where $p$ is the predicted probability of failure and $p$ is the sample frequency of failure. This goodness of fit measure compares then the predictive ability of the probit estimator to that of a naive estimator corresponding to the sample frequency of failure. 
than 90 percent of failures. Interestingly, the cost of this improved predictive ability is low, as more than 75 percent of the successes are still predicted correctly. We must keep in mind that, while this in-sample forecasting ability is impressive, successful out-of-sample forecasting would require an accurate projection of external conditions.

Another interesting result emerging from the process of specification search is that several exogenous variables, initial conditions, and political economy variables remain statistically significant even after controlling for monetary and fiscal adjustment. This reinforces the previous finding about the explanatory power of initial conditions and exogenous controls, as it shows more clearly that the same degree of policy adjustment in different stabilizations may lead to success or failure depending on the evolution of the external environment, the situation of the economy at the beginning of stabilization, and features of the political system. We now proceed to consider the answers that this econometric exercise can provide to some specific questions on the determinants of failed disinflations.

\section{External Conditions: Is Good Luck Important?}

We introduce time-varying exogenous controls in all specifications to control for the effect that external developments may have-directly or indirectly - on the evolution of domestic inflation. Column ( 1$)$ in Table 4 shows that higher U.S. interest rates $\left(U S i_{T+i}\right)$ and a reduction in import demand from trading partners between $T$ and $T+1\left(X D E M_{T+1}-X D E M_{T}\right)$ significantly increase the probability of failure. ${ }^{29}$ The impact of shocks to the import demand from trading partners on the probability of failure is also evident from the bivariate correlations shown in Figure 4. The positive coefficient on the variable interacting U.S. interest rates with the lagged value of the capital account openness dummy $\left(U S i_{T+i}{ }^{*} O P E N K A_{T+i-1}\right.$ in column (3)) indicates that a positive shock to U.S. interest rates increases the probability of failure significantly more in a country with an open capital account. The interpretation of this result is discussed below. The fact that external shocks remain statistically significant after controlling for output growth, international reserve changes, and fiscal and monetary developments is noteworthy and suggests that these shocks have effects beyond the indirect ones captured by those variables. These results are robust to the addition of other explanatory variables and the estimation method.

There is general consensus in the economic literature about the potential disruptive effect of external shocks. This is highlighted in Dornbusch's (1991) model, where successful implementation of a stabilization program requires that the difference between the realization

\footnotetext{
${ }^{29}$ We also experimented with other measures of external shocks by including a terms of trade index and U.S. inflation. They were not statistically significant in any specification with the exception of the terms of trade index, which was statistically significant in the regressions with the continuous dependent variable presented in Subsection III.B.
} 
of a random external variable and domestic absorption exceeds the initial level of reserves. Our results are also related to the empirical work of Easterly et al. (1993) and Calvo, Leiderman, and Reinhart (1993), which show that U.S. affect the supply of capital to emerging markets.

\section{The "Crisis Hypothesis": Do "Bad" Initial Conditions Help?}

The estimates in column (I) of Table 4 show that higher pre-stabilization inflation $\left(\pi_{T-1}\right)$, lower international reserves $\left(R E S_{T-1}\right)$, and a negative output gap $\left(Y G A P_{T-1}\right)^{30}$ increase significantly the likelihood of success. These results are robust to the estimation method (column ( $I$ ) in Tables 4 and 5). Moreover, the pre-stabilization level of inflation remains very significant even after controlling for other sets of variables. This feature is very clear also from Figure 1, which shows that successful stabilizations are associated with higher prestabilization inflation levels.

The effect of "bad" initial conditions has many theoretical underpinnings. One is the "crisis hypothesis" posited by Drazen and Grilli (1993). Although inflation stabilization is beneficial for society as a whole, conflict between two social groups blocks its adoption. ${ }^{31}$ Only when inflation reaches a sufficiently high level, its welfare cost becomes so high that one of the groups accepts shouldering all of the tax burden required by inflation stabilization. Our results suggest that a surge in inflation may not only determine the timing of the initial stabilization but it would also create social and political conditions that might reduce the chances of failure in the following years. The association between a low initial stock of international reserves and a greater probability of success may be interpreted along the same lines, with the depletion of reserves being a proxy for a recent exchange rate crisis.

Other models also predict a positive relationship between high levels of prestabilization inflation and the probability of success, albeit for different reasons. Orphanides and Wilcox (1996) describe an opportunistic central bank that chooses to stabilize whenever pre-stabilization inflation exceeds a given (unobservable) threshold, but not if inflation remains below the threshold. Thus, a nonlinear relationship between the pre-stabilization

${ }^{30}$ Our measure of output gap is based on a Hodrick-Prescott filter. Similar results were obtained extrapolating a linear trend estimated with observations up to the beginning of the stabilization.

${ }^{31}$ Drazen and Easterly (2000) present evidence in support of the crisis hypothesis when inflation reaches extreme levels. 
level of inflation and the probability of stabilization arises: a surge in inflation may trigger a stabilization attempt. ${ }^{32}$ While the "opportunistic" behavior of the central bank would also explain why a successful stabilization tends to coincide or be preceded by a recessionary gap, it could not account for the association between initially low reserves and success, whose only possible explanation seems to be the crisis hypothesis.

\section{Does the Nominal Anchor Matter?}

The estimates in column (1) of Table 4 indicate that ERBS are less likely to fail within the first three post-stabilization years. Table 5 confirms that the effect of $A N C H O R$ is robust to the exclusion of the lagged dependent variable. For two specifications in Table 4 (columns 2 and 3), the Wald test rejects the null hypothesis of $\delta=0$ suggesting that the univariate coefficient estimates might be biased. The $A N C H O R$ coefficient remains, however, negative and statistically significant also in the bivariate probit estimates (columns $(2 \mathrm{BIV}$.) and $(3 \mathrm{BIV}$.) ). Interestingly, the effect of ERBS can only be identified when other determinants of failure are properly controlled for. In our sample, in fact, the frequency of ERBS' failures is similar to that of the entire sample (Table 2).

The role of the nominal anchor in determining the likely success of a stabilization plan is a contentious issue. In the mid-1980s several authors favored the use of the exchange rate (accompanied by other "anchors" such as price and/or wage controls) to act as a coordinating device in order to bring inflation down from chronically high levels at relatively low output costs. ${ }^{33}$ Fischer (1986) shows that exchange-rate based stabilizations are likely to be expansionary, in contrast with money-based stabilizations, which are accompanied by an initial recession. To the extent that positive output dynamics help reinforce the initial adjustment (including through a better fiscal position), exchange rate based stabilizations should be more likely to succeed.

Giavazzi and Pagano (1986) provide another argument in favor of exchange-rate based stabilizations. They explain that a strong commitment to a highly visible variable such as the exchange rate (as opposed to a monetary aggregate) had the advantage of imposing the financial discipline needed to support the peg. This argument, initially developed in the

\footnotetext{
32 In Orphanides (1996b), a higher pre-stabilization level of inflation is more likely to induce a government to embark on stabilization, because it increases the cost of not acting. In Milesi-Ferretti (1995), a higher pre-stabilization level of inflation tilts the cost-benefit analysis made by the incumbent government in favor of embarking on a disinflation strategy, but the predictions of this model are confined to the case of democracies. However, these models also predict that measures aimed at helping a country's citizens to minimize the costs of inflation (such as indexation of nominal contracts) will reduce the likelihood of starting a stabilization for a given inflation rate.

${ }^{33}$ See, for example, Cukierman (1988).
} 
context of a multilateral arrangement (the European Union), gained popularity in the early 1990 s among developing countries (Aghevli, and others (1991)), but was subsequently challenged, both theoretically and empirically. On theoretical grounds, Tornell and Velasco (1995) show that the extent to which a peg imposes fiscal discipline is related to the discount rate of the policymaker and, thus, no generalizations could be made about its benefits.

Finally, it must be stressed that the coordinating and/or discipline role of the exchange rate anchor discussed above relates not only to the behavior of fiscal and monetary variables. A credible exchange rate anchor is expected to be a powerful tool for disciplining wages and interest rates.

Our estimates cannot distinguish between the different roles of an exchange rate target proposed in the literature but indicate that the contribution of an exchange rate anchor to the success of inflation stabilizations goes beyond the positive effect it might have on poststabilization output dynamics and its disciplining role on fiscal and monetary policies. It is noteworthy, in fact, that the coefficient of the ANCHOR dummy remains statistically significant even after controlling for post-stabilization GDP growth and fiscal and monetary adjustment (column (3)). The statistical significance of the exchange rate anchor can then be attributed to its impact as pre-commitment or coordinating device on inflation expectations.

\section{The determinants of ERBS}

To control for the possible endogeneity of the ANCHOR dummy we estimated an auxiliary probit equation for the determinants of ERBS. This equation is of interest on its own merits. Why do certain governments choose to use the exchange rate as a nominal anchor but not others? Table 6 provides some answers. The overall fit of the probit is very good with a pseudo $R^{2}=0.804$ and over 90 percent of correct predictions at all the probability threshold levels considered, including the sample frequency of ERBS (26 percent). The dummy for African and Middle-Eastern countries $(A F R M E)$, included to ensure identification of the bivariate probit (see Subsection II.F), is statistically significant. ERBS tend to be chosen by countries with higher initial GDP per capita $\left(G D P P C_{T}\right)$, larger initial stock of international reserves $\left(R E S_{T-1}\right),{ }^{34}$ more favorable fiscal balances $\left(G B_{T-1}\right)$, and higher initial GDP growth $\left(G D P_{T-1}\right)$. A more depreciated real exchange rate prior to the stabilization $\left(\right.$ RERGAP $\left.P_{T-2}\right)$ also tends to be associated with ERBS. An open current account (OPENCA $\left.A_{T-1}\right)$ increases the chances that a country might choose an exchange-rate-based stabilization, as could be expected since an exchange rate anchor can be more effective at disciplining domestic prices the more open the economy is. We also find that an open capital account (OPENKA $A_{T-1}$ ) reduces the probability of choosing an exchange-rate-based stabilization; this result could reflect the fact that countries may be less willing to commit to an exchange rate target in the presence of volatile capital flows.

\footnotetext{
${ }^{34}$ Using fewer regressors and a smaller sample, Gould (2001) also finds that the prestabilization level of international reserves is a significant predictor of ERBS.
} 
Table 6. ANCHOR Estimates

(Heteroskedastic corrected standard errors in parenthesis)

\begin{tabular}{|c|c|}
\hline AFRME & $\begin{array}{l}-3.400 * * \\
(1.411)\end{array}$ \\
\hline$G D P P C_{T}$ & 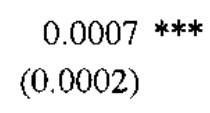 \\
\hline$R E S_{T-1}$ & $\begin{array}{c}0.231 \\
(0.117)\end{array}$ \\
\hline$G B_{T-1}$ & $\begin{array}{l}32.664 \text { *** } \\
(11.189)\end{array}$ \\
\hline$G D P_{T-1}$ & $\begin{array}{l}41.709^{* * *} \\
(14.279)\end{array}$ \\
\hline$R E R G A P_{T-2}$ & $\begin{array}{l}-13.319 * * * \\
(3.690)\end{array}$ \\
\hline$O_{P E N C A}{ }_{T-1}$ & $\begin{array}{l}6.798^{* * *} \\
(1.887)\end{array}$ \\
\hline OPENKA T-1 & $\begin{array}{l}-5.451 * * * \\
(1.903)\end{array}$ \\
\hline$Y E A R S_{x>10}$ & $\begin{array}{c}0.326^{* *} \\
(0.139)\end{array}$ \\
\hline$X_{\text {CONST }}$ & $\begin{array}{c}0.606^{* *} \\
(0.248)\end{array}$ \\
\hline Constant & $\begin{array}{l}-10.041^{* * *} \\
(2.218)\end{array}$ \\
\hline Pseudo $R^{2}$ & 0.804 \\
\hline Efron's $R^{2}$ & 0.801 \\
\hline Percent of hits $\left(p^{*}=0.5\right)$ & $' 94.0$ \\
\hline Percent of hits $(p *=0.26)$ & 92.0 \\
\hline Percent of hits $\left(p^{*}=0.1\right)$ & '92.0 \\
\hline Percent of $A N C H O R=1$ hits $\left(p^{*}=0.1\right)$ & 92.3 \\
\hline Percent of $A N C H O R=0$ hits $\left(p^{*}=0.1\right)$ & '91.9 \\
\hline Number of observations & 50 \\
\hline
\end{tabular}

Note: Data are annual. Three $\left({ }^{* *}\right)$, two $\left({ }^{* *}\right)$, and one $\left({ }^{*}\right)$ asterisks mark statistical significance at respectively 1,5 , and 10 percent levels. 
We also find some evidence that exchange rate anchors tend to be used in countries with a long history of high inflation $\left(Y E A R S_{\gtrsim \succ 40)}\right.$. Moreover, we find that an important feature of the political institutions of a country contributes to determine the choice of the nominal anchor. The more severe are the institutional constraints of the executive authoritymeasured by the variable $X C O N S T_{0}$ the more likely the country is to choose the exchange rate as a nominal anchor. ${ }^{35}$ This result merits further investigation but suggests that countries where the government is more constrained by the legislature tend to choose an exchange rate anchor to stabilize, consistently with its predicted disciplining and pre-commitment role.

\section{The Role of Real and Financial Openness}

The degree of openness of the economy is another potentially important determinant of the success or failure of disinflation. We measure it with two dummy variables taking on values of one in the absence of restrictions on current account and capital account transactions respectively. The estimates in column (1) of Table 4 indicate that both a high degree of current account $\left(O P E N C A_{T-1}\right)$ and capital account $\left(O P E N K A_{T-1}\right)$ openness prior to stabilization reduces significantly the chances of failure. The effect of the openness of the current account is, however, not robust, as $O P E N C A_{T-1}$ drops out in the specification with political economy variables (column (2)). This may reflect the fact that the openness of the current account is actually proxying for other political and institutional features of the country. The effect of the openness of the capital account survives, instead, the inclusion of other sets of variables and is also robust to dropping $F A I L 1_{T+i-1}$ (Table 5). Interestingly, however, countries with an open capital account tend to be more vulnerable to international interest rate shocks.

These results are broadly in line with the existing literature. Building on Kydland and Prescott (1977), Romer (1993) explains the link between real openness and low inflation by showing that the magnitude of the inflation bias in the absence of a pre-commitment

${ }^{35}$ This variable (obtained from the POLITY IV dataset, see Data Appendix) takes values ranging from 1 ("unlimited executive authority") to 7 ("executive parity or subordination") and aims at measuring the extent of the institutional constraints on the decision-making powers of the chief executive, whether an individual or a collective executive. This variable captures the degree of checks and balances between the various parts of the government. In Western democracies the executive branch is typically constrained by the legislative and judicial branches of government. Certain institutional constraints may bind, however, also the chief executive of nondemocratic regimes. Examples of accountability groups in this case are a ruling party in a one-party system or the military in coup-prone countries. 
technology in monetary policy is inversely related to the degree of openness of the economy: greater openness reduces the response of output to an unexpected increase in demand. ${ }^{36}$ Romer finds that inflation tends to be consistently higher in less open economies - with the exception of a small group of low inflation, industrialized countries. Romer's results are intended to capture mainly cross-country differences, with the degree of openness considered an exogenous variable. Lane (1997) re-examines the issue within a richer economic structure and finds the same result: an inverse relationship between openness and the time consistent discretionary inflation rate. However, Lane derives a clear policy implication from his results: trade liberalization may lead to a concomitant reduction in inflation.

Dornbusch (1991) contains a simple analysis of the role of an open capital account in determining the success of inflation stabilization. He finds a Stackelberg solution to his oneshot stabilization game (the government selects its adjustment effort first, speculators make their decision next) in which, with an open capital account, stabilization benefits from a multiplier effect derived from supportive speculation. Although the possibility of speculative inflows renders the magnitude of the optimal adjustment effort uncertain, Dornbusch finds a general set of conditions under which both the optimal adjustment effort and the probability of success increase. However, he also shows that under other circumstances increased capital mobility may reduce the probability of success. This ambiguous effect of capital account openness is consistent with our estimation results, as the increased vulnerability to international interest rates shocks during the adjustment phase might offset the reduction in the likelihood of failure due to an open capital account.

Orphanides (1996a) examines the role of an open capital account and the role of prospective speculative capital flows in a dynamic setting. He finds that the optimal intertemporal distribution of adjustment (between two stabilization stages) is affected by the prospect of supportive speculation: it is optimal to frontload adjustment to deliberately increase the perceived likelihood of completion, which triggers capital inflows and reduces the magnitude of the needed adjustment in the second stage, thus increasing the probability of completion.

\section{State Dependence: Do Past Failures Reduce the Chances of Success?}

The results in Table 4 provide two indications on the relevance of state dependence in inflation stabilizations. First, a long history of high inflation, measured by the number of pre-stabilization years in which inflation has remained above 40 percent $\left(Y E A R S_{\pi>40}\right)$, tends to increase the probability of failure. This initial condition remains significant when we add other regressors and drop $F A I L 1_{T+i-1}$. Second, column (1) seems to suggest that there is also in-sample state dependence. The positive coefficient on $F A I L_{T+i-1}$ indicates that failure

\footnotetext{
${ }^{36}$ This occurs through a direct channel (part of the expansion in demand is spent on foreign goods), and an indirect channel (the expansion in demand leads to a deterioration in the country's terms of trade).
} 
(success) in periods $T+1$ or $T+2$ tends to be followed by failure (success) in the following period. This variable, however, is no longer statistically significant when we add policy and nonpolicy macroeconomic variables, which could indicate that this form of state dependence may be spurious and due to omitted adjustment variables in the specifications of columns 1 and 2. However, in the regressions with FAIL2 and RATIO, presented in Subsection III.B, the lagged dependent variable never drops out of the regression.

The statistical significance of the length of the pre-stabilization period with high inflation in reducing the chances of a successful stabilization has several possible interpretations. First, it may simply reflect reputational and credibility factors. The longer a country has experienced high inflation, the smaller its anti-inflation reputation, and, ceteris paribus, the more likely is the stabilization to fail. A credibility argument can also explain in-sample state dependence: initially successful stabilizations increase the government's credibility and make the continuation of the stabilization easier, while the opposite happens when stabilizations fail already in period $T+1$ or $T+2$. The role of reputation and credibility has been extensively studied in the literature on inflation stabilization (see the critical survey of the literature in Rogoff (1987)).

Second, given that long periods of high inflation also tend to be associated with a high degree of wage and interest rate indexation, $Y E A R S_{\pi>40}$ can also be proxying for the presence of indexation, confirming the traditional view that indexation tends to make inflation stabilization more difficult.

Third, the positive effect of $Y E A R S_{\pi>40}$ on the probability of failure may be interpreted within the framework of Dornbusch (1991) model as a proxy for the political marginal cost of failure. A long history of high inflation may indicate that the government has lost a significant amount of political capital with each failed stabilization. Thus, a higher value of $Y E A R S_{\pi>40}$ would suggest that the marginal political cost of failure is low and the probability of another failure is higher.

Interestingly, the positive coefficient on $Y E A R S_{\pi>40}$ is inconsistent with Alesina and Drazen's (1991) war of attrition model. In that model, stabilization would be preceded by a protracted period of high inflation. As time goes by, the costs of inflation pile up and the likelihood that one of the two groups involved in the war of attrition gives up, allowing the stabilization to succeed, increases. Accordingly, the longer the pre-stabilization period of high inflation, the more likely should be that a solution to the underlying social conflict is found, so that stabilization can start and be successfully completed. This interpretation would imply a negative coefficient on $Y E A R S_{\pi>40}$, which is not what we find. However, we must stress that this result by itself does not necessarily disprove war of attrition stories of the timing of stabilization. Our estimated coefficient simply suggests that low anti-inflation credibility, the presence of indexation, or a lower marginal political cost of failing in yet another attempt may all be important determinants of failure. 


\section{The Role of Political Institutions and Conditions}

Column (2) in Table 4 shows the effect of including variables measuring political institutions and conditions in the probit regression. The pseudo- $R^{2}$ increases from 0.492 to 0.577 and the predictive power of the model improves, especially its ability to predict correctly successful stabilizations $(F A I L I=0)$. The inclusion of this set of variables makes statistically insignificant the dummy measuring whether the current account was open prior to the stabilization $\left(O P E N C A_{T-1}\right)$ and the pre-stabilization output gap $\left(Y G A P_{T-1}\right)$, which are dropped from the regression.

Our sample spans a wide range of political institutions and includes several major transitions (pre-stabilization or in-sample) from one political regime to another. As several political regimes are not democratic, it is essential to control for the existence of a democratic regime before considering other features of democratic political institutions such as, for example, the electoral system.

To study the effect of political economy variables that are relevant only for democracies, we build a zero-one dummy taking value one in those years and countries that have a positive polity index in the POLITY IV dataset. ${ }^{37}$ To assess the relative importance of different features of the political regime on the likelihood of a successful inflation stabilization, we experiment in our regressions with the six component variables of the democracy and autocracy indices, as well as with a variable measuring the durability of the political regime (defined as the number of years since the most recent three-point change in the polity score over a period of three years or less). We find three of these variables to be statistically significant $\left(D U R R E G_{T}, X C O N S T_{T+i-1}\right.$, and $\left.X R O P E N_{T+j-1}\right)$

\section{Countries with long-lived political institutions are more likely to succeed}

Column (2) in Table 4 shows that the durability of the political regime at the start of the stabilization $\left(D U R R E G_{T}\right)$ tends to reduce the likelihood of failure, suggesting that countries with long-standing political institutions are more likely to sustain the stabilization effort. As $D U R R E G_{T}$ remains statistically significant when we add policy and nonpolicy macro variables (column (3)), the role of the durability of the political regime goes beyond predicting successful fiscal and monetary adjustment and may reflect the initial positive

${ }^{37}$ The POLITY IV dataset classifies political regimes on the basis of six variables corresponding to three features of the chief executive recruitment process (regulation, competitiveness, and openness), the independence of the executive authority, and two features of political competition (regulation and competitiveness of participation). These indices are then combined to obtain two summary indices of democracy and autocracy, each ranging from zero to 10 . The difference between the democracy and autocracy index yields a polity index ranging from -10 to +10 with political systems being usually considered democracies only when the polity index is positive. We follow the same convention in building our zero-one democracy dummy. 
effect of lasting political regimes on expectations and credibility. This effect is also robust to

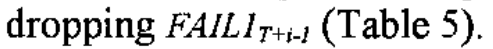

The importance of the durability of the political regime has a theoretical underpinning in previous studies that highlight how political instability can explain high inflation and reliance on seigniorage as a source of revenue (Cukierman, Edwards, and Tabellini (1992)). This prediction reflects a strategic behavior on part of the government. If a government is uncertain about being reappointed, it has an incentive to maintain the inefficient tax system associated with high levels of seigniorage in order to constrain the action of future governments and discourage them "from collecting taxes and spending them on goods that are not valued by the incumbent policymaker." Of course, the more polarized is the political system (i.e., the greater the difference in preferences between the incumbent government and its potential successors), the greater is the strategic incentive to use the inflation tax. While this model has been generally tested by constructing a measure of political instability based on transfers of power and government changes, rather than political regime changes as in this paper, we think that for the countries in our sample-many of which experienced several transitions from and to democracy over a relatively short horizon - the durability of the political regime is the appropriate measure of political stability. (We also tried alternative measures of political instability based on the frequency of past government changes but they were not statistically significant.)

\section{A weak executive authority is more likely to fail}

A second result regarding the role of political institutions is that the larger are the institutional constraints of the chief executive $\left(X C O N S T_{T+i-1}\right)$ the more likely is stabilization to fail. ${ }^{38}$ We lag XCONST one period to avoid simultaneity problems. The statistical significance of this variable is robust to the exclusion of FAIL $1_{T+i-1}$ and to the estimation method. An obvious question raised by this result is whether the statistical significance of $X C O N S T_{T+i-1}$ is entirely attributable to the effect of some successful inflation stabilizations performed in our sample by nondemocratic regimes (for example, Chile 1975 or Brazil 1966.) The answer is no. If we estimate two separate coefficients of $X C O N S T_{T+i-I}$ for democratic and nondemocratic regimes, we find that they are both positive and statistically significant, and not significantly different. This indicates that the institutional constraints of the chief executive have an impact on the probability of stabilization failure in both democracies and nondemocracies.

To the extent that democratic presidential systems are associated with fewer institutional constraints on the chief executive, the statistical significance of $X C O N S T_{T+i-1}$ may suggest that presidential systems are less likely to fail. We can check this hypothesis using Persson and Tabellini's (2001a) classification of presidential and parliamentary systems based on whether the executive is accountable to the legislature through a vote of

\footnotetext{
${ }^{38}$ This variable takes values ranging from 1 ("unlimited executive authority") to 7 ("executive parity or subordination").
} 
confidence. We find that the two measures are indeed related. In the subsample of observations corresponding to democracies, almost all parliamentarian regimes (93 percent) have an XCONST value of 7, corresponding to the maximum level of constraints of the chief executive. While some 46 percent of the presidential systems are equally constrained, the rest has lower XCONST scores. The finer distinction provided by the XCONST variable is, however, important because using the Persson and Tabellini's dummy for presidential systems we could not find a statistically significant effect of presidential regimes.

Column (2) in Table 4 shows that greater openness in the chief executive recruitment process $\left(X R O P E N_{T+i-1}\right)$ also tends to be associated with a smaller likelihood of failure. $X R O P E N_{T+i-1}$ remains statistically significant when we add the adjustment variables. Different estimation methods confirm these findings. As high values of $X R O P E N_{T+i-1}$ tend to be associated with democratic regimes, these results suggest that, while constraints on the chief executive tend to increase the likelihood of stabilization failure, selecting the chief executive through an open process contribute to the success of inflation stabilization.

\section{Democracies with majoritarian electoral rules tend to succeed}

The last political institution we consider is the electoral system. We distinguish between proportional electoral systems (in which parties receive seats in strict proportion to their overall vote total) and majoritarian electoral systems (in which only the winner of the highest share of votes in any given district gets a seat. ${ }^{39}$ As majoritarian systems have been found to be associated with smaller levels of government expenditure, ${ }^{40}$ and given the fiscal origin of many inflationary problems, we check whether disinflations are less likely to fail in the presence of majoritarian electoral systems by creating a zero-one dummy that takes value one when the electoral system is majoritarian and the political system is democratic. We lag this dummy one period to avoid simultaneity problems $\left(M A J_{T+i-1}\right)$. Unfortunately, we cannot estimate its effect on $F A I L 1$ because $M A J_{T+i-1}$ is too successful: whenever an electoral system is majoritarian, FAILI takes value zero indicating that the stabilization does not fail. As a result, probit estimates cannot be performed. When we use, however, the two alternative measures of failure discussed in Subsection III.B (FAIL2 and RATIO), we do not have this perfect prediction problem and we find that $M A J_{T+i-1}$ significantly reduces the chances of stabilization failure.

\footnotetext{
${ }^{39}$ As in Persson and Tabellini's (2001a), we neglect the district size, which for many countries in the sample would be unavailable, in characterizing the electoral system.

${ }^{40}$ Persson (2001) and Persson and Tabellini (2001a,b). See also Milesi-Ferretti, Perotti, and Rostagno (2001) on the effects of the size of electoral districts - as a measure of majoritarian versus proportional electoral systems - on government expenditure composition. Persson, Tabellini, and Trebbi (2000) have extended this analysis to the study of the impact of political institutions on corruption.
} 


\section{New governments are less likely to fail}

The zero-one dummy $C E_{\text {years }<=3}$ takes value one when the chief executive of the country has been in power for less than three years. ${ }^{41}$ The estimated coefficient indicates that new chief executives are less likely to fail. Reputational models of monetary policy in which the public is unsure about the policymaker's ability to pre-commit to a low level of inflation (Barro, 1986) or about its inflation preferences (Vickers, 1986) provide a possible explanation of this result. Barro's model, in particular, predicts that, for long enough terms in office, there will be no inflation in the early periods of a term regardless of which type the policymaker actually is. Similarly, as long as pooling equilibria prevail at the beginning of a term, inflation will be lower when a new chief executive is in power also in Vickers' model regardless of its inflation preferences. Political business cycle models in which governments are more inclined to take unpopular measures at the beginning of their terms provide another possible justification for this result (Nordhaus, 1975.)

The greater success of new chief executives can also be explained otherwise. Persson and Tabellini (1990), for example, propose a model in which unexpected policy actions disrupt the system of expectations of private agents but a new government has the potential for stabilizing these expectations as the economy focuses on a new set of policy proposals. In this case, new chief executives would be more likely to succeed because they could benefit from more favorable expectations. Finally, new chief executives may stand to loose more political capital in case of failure and, according to Dornbusch's (1991) model, may choose a greater adjustment. Our estimation results allow us to partially discriminate among these alternative explanations. The fact that $C E_{\text {years }<=3}$ remains statistically significant after we control for the adjustment variables suggests that reputational and expectational factors are important and that this variable is not only a proxy of adjustment.

\section{How does social and political cohesion matter?}

A divided and polarized government, a split between the executive authority and the legislature, or social tensions could be symptoms of an ongoing "war of attrition"-as described in Alesina and Drazen (1991) and Drazen and Grilli (1993) - that might postpone the stabilization of inflation or cause the failure of an initially successful attempt.

We considered three measures of political cohesion. The first two indices are the Roubini and Sachs (1989) index and the government polarization index from the Database of Political Institutions of the World Bank. The Roubini and Sachs index ranges from zero to three with 0 corresponding to the maximum of political cohesion (a one-party majority

${ }^{41} C E_{\text {years }<=3}$ should not be confused with $D U R R E G_{T}$, which measures the durability of the political regime (i.e. of the political institutions of a country.) For example, the dummy $C E_{\text {years }<=3}$ may take value 1 to indicate that a new chief executive is in power, even if $D U R R E G_{T}$ is high because the political institutions of the country have not changed for many years. 
parliamentary government or a presidential government, with the same party in the majority in the executive and legislative branch ) and three to the minimum (minority parliamentary government). The polarization index ranges from zero to two and measures the maximum difference of orientation among government parties. The third is an index of party coalitions from Banks' Cross-National Time-Series Data Archive that ranges from zero to three. As the three indices are highly correlated and tend to perform similarly in the regressions, we construct an index corresponding to their first principal component, which accounts for about 70 percent of the overall variance $\left(P O L I N C O H_{T+i-1}\right)$. We lag the index one period to avoid simultaneity problems.

Contrary to the theoretical predictions, the estimated coefficient of $P O L I N C O H_{T+i-1}$ is negative suggesting that less cohesive governments are less likely to fail. This result is robust to the addition of the adjustment variables and to the estimation technique. As shown in Subsection III.B, these estimates are also robust to the variable used to measure stabilization failure. While this result is puzzling at first sight, it reflects the fact that some successful disinflations were implemented by "national unity" coalitions among the major parties in parliament (for example, Israel 1986) or by minority governments that reached an agreement with opposition parties. Once these broad-based stabilization efforts begin, they may be more likely to be sustained over time because all the key political players have a stake in the success of the stabilization and few can benefit from its failure. This evidence casts some doubts on the mechanism through which war of attrition models foresee the end of a high inflation episode. According to these models, the end of high inflations should be associated with one of the two groups involved in the war attrition giving up and suffering the redistributive costs of the stabilization. By contrast, our estimates suggest that some stabilizations are associated with a cooperative agreement among the major parties. Further research could investigate whether this result might depend on our focus on the durability of stabilization attempts and on high - as opposed to moderate-inflation stabilizations.

Finally, we consider whether an indicator of social tensions based on the number of strikes, anti-government demonstrations, and riots, tends to increase the probability of stabilization failure. We obtain these three variables from Banks' Cross-National TimeSeries Data Archive and then, to limit the number of regressors, we construct an index corresponding to their first principal component, which accounts for about 60 percent of the overall variance. As the impact of social tensions is likely to be time and country specific, we use as a regressor the lagged deviation of this index from its moving average over the previous three years $\left(S O C C O N F_{T+i-1}\right)$. An increase in this variable would then measure an increase in social tensions in relation to the previous three years. We lag this measure to avoid simultaneity problems. Table 4 shows that an increase in $S O C C O N F_{T+i-1}$ tends to augment the probability of stabilization failure as predicted by war of attrition models. This result is confirmed when we add adjustment variables or we estimate a static regression. Other proxies of social fragmentation, such as, for example, a measure of ethno-linguistic fractionalization, were not statistically significant. 


\section{The contribution of nonpolicy and policy macroeconomic variables}

Column (3) in Table 4 presents the results of a specification search that takes into account a set of nonpolicy and policy macro variables. These variables improve the fit of the regression further with the pseudo- $\mathrm{R}^{2}$ increasing from 0.577 to 0.863 and the precision with which successful stabilizations are predicted.

\section{The contribution of nonpolicy macroeconomic variables}

We find four statistically significant nonpolicy adjustment variables: a measure of real exchange rate appreciation $\left(R E R_{N O F A L_{T+i-1}}\right)$, GDP growth $\left(G D P_{T+i-1}\right)$, the increase in international reserves as a ratio to imports from year T-1 $\left(R E S_{T+i-1}-R E S_{T-1}\right){ }^{42}$ and a variable interacting the level of U.S. interest rates at time $T+i$ with a dummy indicating whether the capital account was open in time $T+i-1\left(U S i_{T+i} * O P E N K A_{T+i-1}\right.$. $)$ All variables are lagged one period to avoid simultaneity problems. The inclusion of this set of adjustment variables makes statistically insignificant the pre-stabilization stock of international reserves $\left(R E S_{T-1}\right)$, which is dropped from the regression together with $F_{A L I}+i-1,(i=2,3)$. We have already commented on the significance of $U S i_{T+i} * O P E N K A_{T+i-I}$ and on the implications of the nonsignificance of the lagged dependent variable. We shall then discuss only the other results.

To estimate the effect of real exchange rate appreciation on the probability of failure, we control for whether the stabilization has already failed or not. Specifically, the real exchange rate in period $T+i-I$ contributes to explain the stabilization outcome in period $T+i$ only if the stabilization has not yet failed in period $T+i-I .{ }^{43}$ Conditioning the effect of the real exchange rate on the continuation of a successful stabilization is important because stabilization failures tend to be associated with large real depreciations. As a result, introducing the real exchange rate among the regressors without controlling for whether the stabilization has yet failed would result in appreciated real exchange rates being associated with successful stabilizations and depreciated real exchange rates being associated with failures. The interesting question is, instead, whether successful stabilizations that have experienced a real appreciation are more likely to fail in the following period. The answer to this question is positive as indicated by the statistically significant positive coefficient on $R_{E R N_{N A I L}+i-1}$. It is important to note that, as the effect of the real exchange rate appreciation is conditioned on the past success of stabilization, in-sample state dependence continues to

\footnotetext{
${ }^{42} \mathrm{We}$ also tried to measure reserves as a ratio to $\mathrm{M} 2$ but the fit was better with the ratio to imports.

${ }^{43}$ The variable RERNOFALLT+i-1 is derived by multiplying a real exchange rate index $\left(R E R_{T+i-1}\right)$ - equal to 100 in period $T$--by a zero-one dummy taking value one when the stabilization has not yet failed in period $T+i-1\left(1-F A I L 1_{T+i-1}\right)$. We also set RERNOFAIL $_{T+i-1}$ to zero in period $T+l$ because the lagged value of $R E R$ in $T+l$ is equal to 100 for all countries and it would be meaningless to try to use this constant value to explain the stabilization outcome in period $T+I$.
} 
play a role also in the estimates of columns (3), even though it does not appear independently as $F A I L 1_{T+i-1}$.

Lagged GDP growth $\left(G D P_{T+i-1}\right)$ tends to reduce the chances of failure. Positive growth may contribute to the success of inflation stabilization both directly by improving the fiscal position of the government and indirectly by creating the necessary consensus to sustain the adjustment effort. This positive association between growth and successful stabilizations emerges very clearly also from the bivariate correlations shown in Figure 5. This result indicates that, in our sample of high inflation stabilizations, there is no evidence of the "sacrifice ratio" (in terms of foregone GDP growth) found by Ball (1994) for industrial countries. This evidence is consistent with the findings of the literature on ERBS but our results suggest that the positive association with growth extends to the wider category of successful stabilizations. ${ }^{44}$ This result needs, however, to be qualified further. The estimates with the other two measures of stabilization failure discussed in Subsection III.B show that, during the adjustment phase, not only GDP growth but also the output gap matters, with more positive output gaps being associated with failures. (In the regressions with FAIL1, the output gap had the same sign we found in the estimates with FAIL2 and RATIO but it was not statistically significant.) This suggests that growth is beneficial as long as it does not cause the economy to grow above potential. The bivariate correlations shown in Figure 6 are consistent with this interpretation.

The estimates in column (3) indicate that an increase in international reserves from year T-1 $\left(R E S_{T+i-l}-R E S_{T-1}\right)$ is associated with successful stabilizations. This is evident also from the bivariate analysis in Figure 7. An increase in international reserves may be important because it reduces the vulnerability of the stabilization program to external shocks or because it reflects confidence effects, especially in the case of ERBS. This interpretation has solid foundations in the theoretical literature.

In Dornbusch (1991), a successful stabilization program may be associated with a net outflow of foreign exchange; however, this outflow must not exceed the initial level of reserves. Thus, a higher level of reserves increases the likelihood of success. A similar condition is required for the successful completion of a stabilization in Orphanides (1996a, 1996b). However, in those models the stock of reserves plays a more complicated role. First, as in Dornbusch (1991), it directly increases the chances of success of a program for a given adjustment effort, and thus, the likelihood that it will be implemented. Second, since (i) the necessary degree of adjustment is a decreasing function of the stock of reserves, and (ii) the current level of reserves is subject to a stochastic component, a positive shock to available reserves reduces the magnitude (and its associated welfare cost) of adjustment and, thus, makes it more likely that a stabilization will be implemented. Orphanides (1996a) shows that, having decided to start a program, a government facing a positive shock on reserves during

${ }^{44}$ Gould (2001) also points out that the positive correlation between inflation stabilization and growth is not limited to ERBS. 
Figure 5. Growth in Per Capita GDP

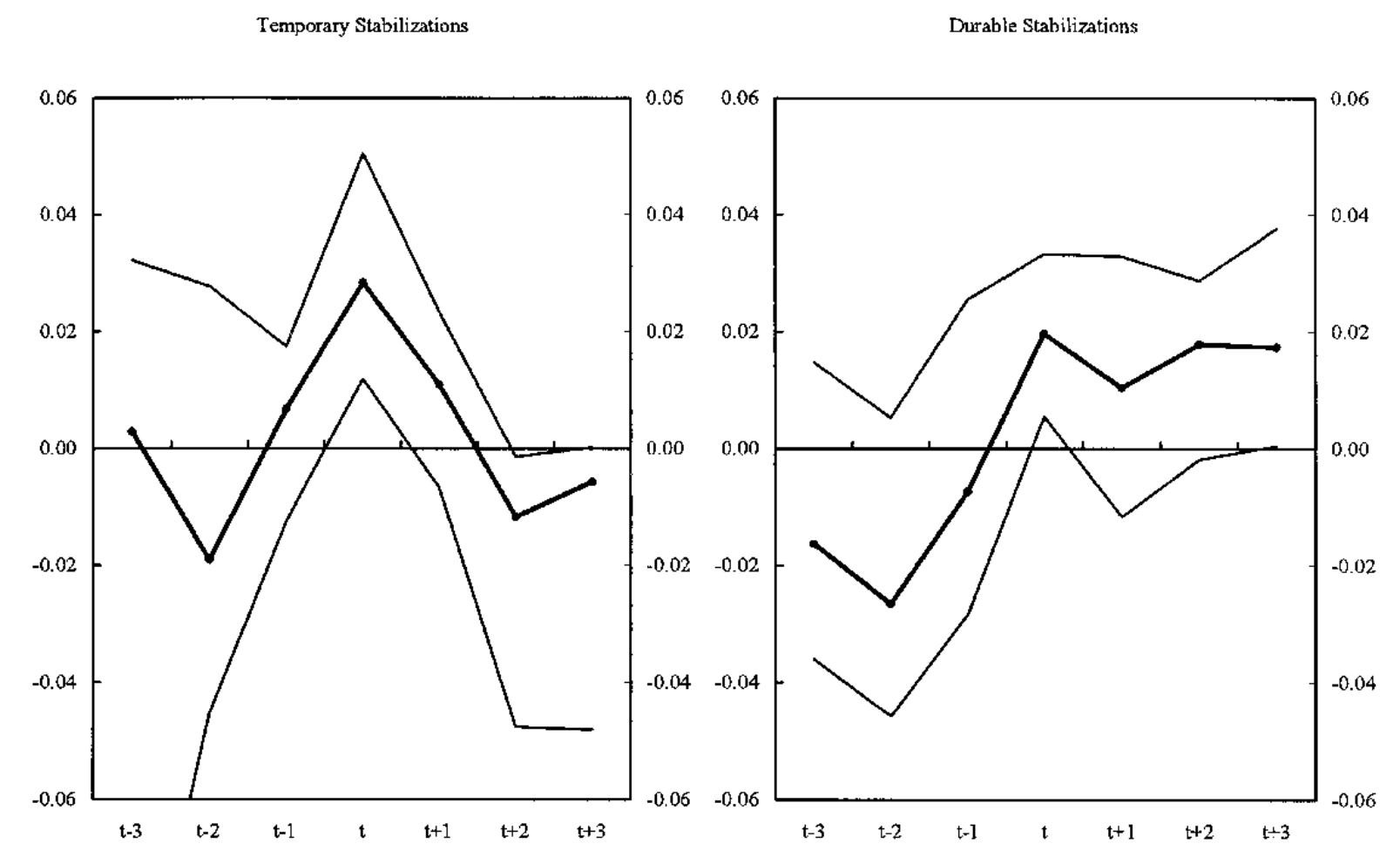

Source: IMF, International Financial Statistics; national sources; and authors' own estimates. 
Figure 6. Output Gaps

(In percent of potential GDP)

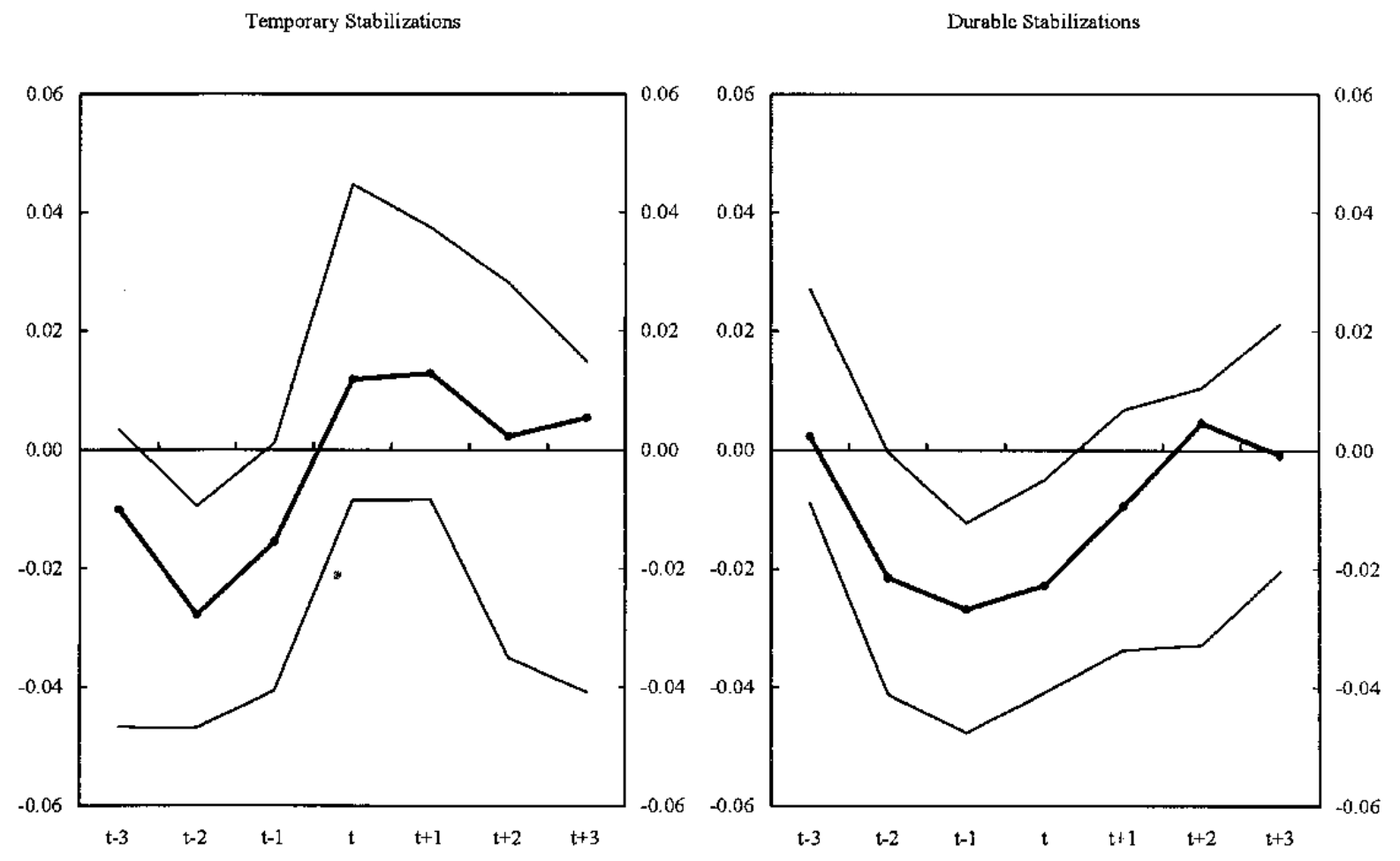

Sources: IMF, International Financial Statistics; national sources; and authors' own estimates. 
Figure 7. Gross International Reserves

(In months of Imports)

Temporary Stabilizations:

International Reserves
Durable Stabilizations:

International Reserves

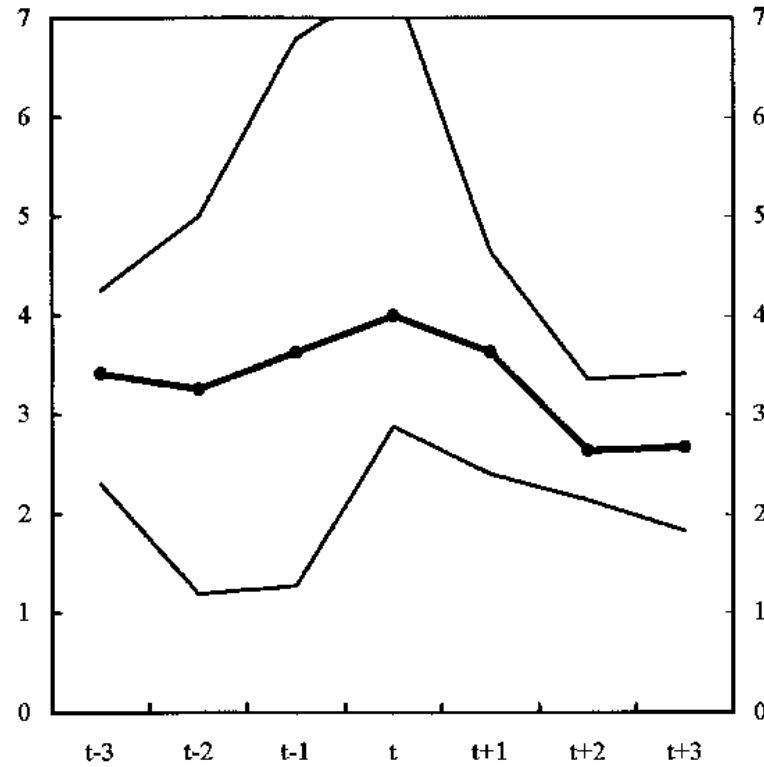

Temporary Stabilizations:

Deviations from Value in Year $t$

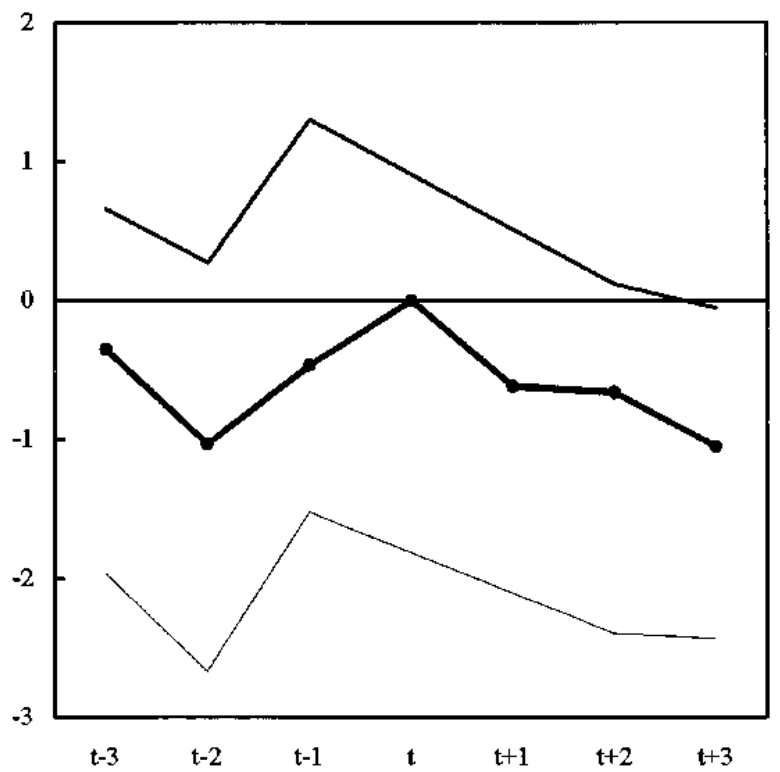

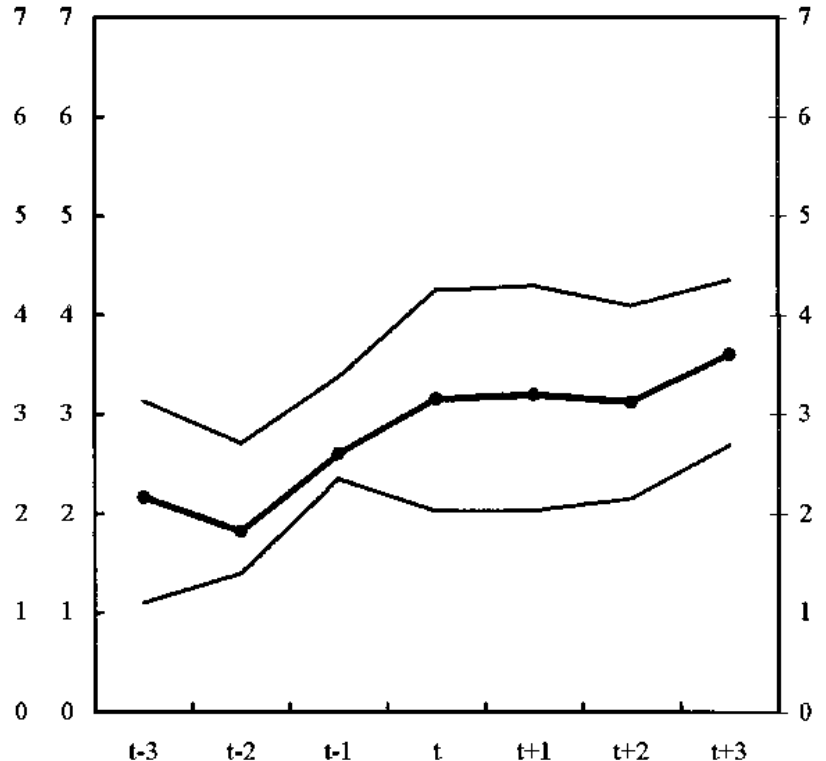

Durable Stabilizations:

Deviations from Value in Year $t$

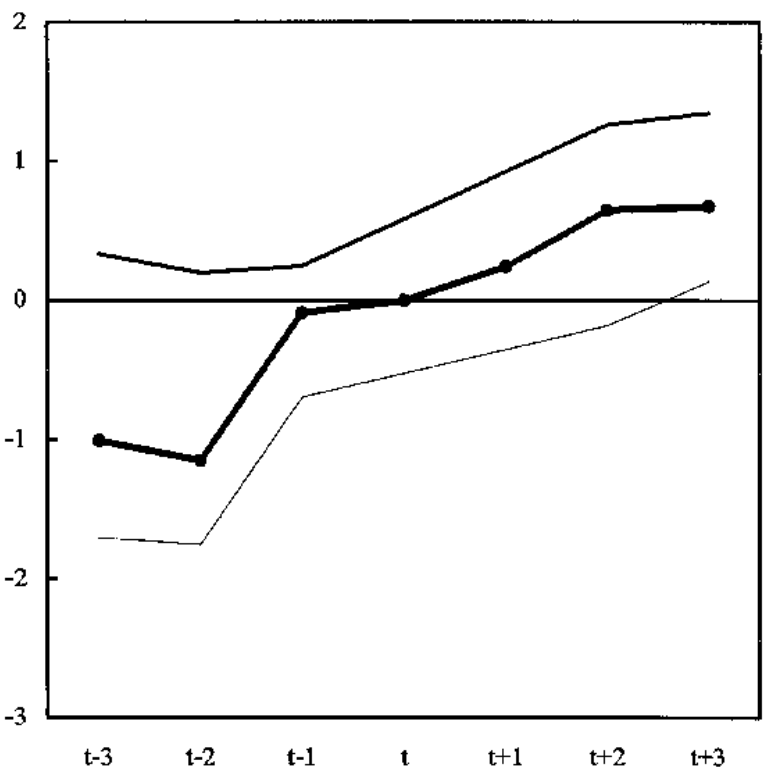

Sources: IMF, International Financial Statistics; national sources; and authors' own estimates. 
the first stage of stabilization will be more likely to complete its adjustment in the second stage, as the needed second dosage of adjustment will also be lower. Werner (1999) also shows that a high initial stock of reserves increases the likelihood that the first stage of stabilization will be undertaken since a loss in reserves is needed during the first stage (when inflation is lowered by pegging the exchange rate but not adjusting domestic absorption). ${ }^{45}$

\section{The impact of policy macroeconomic variables}

Consistently with the bivariate association shown in Figures 2 and 3, the change in fiscal balances $\left(G B_{T+i-1}-G B_{T}\right)$ and bank credit growth $\left(D C_{T+i-1}\right)$ are statistically significant with the expected signs. These results are robust to the estimation method and confirmed in the static regression. This fact is noteworthy because it indicates that the same fiscal and monetary adjustment may result in a stabilization success or in a failure depending crucially on the realization of the many other factors we identified in the previous regressions.

It is also remarkable that both fiscal and monetary adjustment are statistically significant. The fact that the fiscal adjustment variable remains statistically significant even after controlling for domestic credit growth suggests that smaller fiscal deficits have an effect on the disinflation process over and above their mechanical direct effect on monetary aggregates via a smaller monetization. It is also interesting that fiscal balances continue to play a role after controlling for GDP growth, whose statistical significance may in part reflect the positive effect that growth is bound to have on fiscal adjustment. Conversely, the fact that domestic credit growth remains statistically significant even after controlling for fiscal developments suggests that - at least in this sample of countries and with this measure of stabilization failure - fiscal developments do not fully account for disinflation and that domestic credit conditions are also important. This is consistent with stabilizations in which the initial fiscal tightening is accompanied by capital inflows that lead to a domestic credit boom and ultimately to the failure of the stabilization. ${ }^{46}$

There is no lack of reference to the importance of monetary and fiscal adjustment in the theoretical (and policy) literature on inflation stabilization. In the Dornbusch (1991) model, for example, as well as in the extensions by Orphanides (1996a, 1996b), adjustment plays a key role. Macroeconomic adjustment is typically modeled as a reduction in domestic

\footnotetext{
45 The author also shows that a government without enough reserves can undertake the first stage of stabilization if it can borrow abroad. In this case, the higher the interest rate paid on public debt, the stronger the needed adjustment will be in stage two and, thus, the less likely that stage two will be successfully implemented.

${ }^{46}$ We also experimented with a lending boom measure equal to the lagged difference of domestic credit growth and nominal GDP growth, which was not statistically significant.
} 
absorption, which can be easily associated with fiscal retrenchment or a tightening of monetary conditions. ${ }^{47}$

Alfaro (1999) and Werner (1999) provide another interesting perspective on the role of adjustment by studying why it may be optimal to undertake stabilizations that are doomed to fail, where failure is associated with the lack of adoption of meaningful macroeconomic adjustment. Alfaro (1999) models temporary exchange rate based stabilizations that are not sustainable in the long-run, because they are not accompanied by the necessary supporting fiscal policies. She focuses on the distributive consequences of temporary policies in a setting where economic agents differ in their initial endowments (tradable vs. non tradable goods). An unsustainable exchange-rate-based stabilization is shown to be a way to engineer a large real exchange rate appreciation and a transfer of resources in favor of the nontradable sector and, thus, a rational political decision aimed at favoring a given group in society. In Werner's (1999) two-stage model, the first step of stabilization is also modeled as an eventually unsustainable exchange-rate-based stabilization. However, its implementation is aimed at building a consensus (economic agents learn gradually about the benefits of lower inflation) to implement the fiscal adjustment needed for the ultimate success of the stabilization plan. In the absence of a good understanding of the benefits of low inflation, fiscal adjustment would be rejected by the population.

\section{B. Robustness to Different Measures of Failure}

In Tables 7 and 8 we present the dynamic regressions for the dichotomous measure of failure FAIL2 and the continuous measure RATIO. In the case of FAIL2, we present the pooled regression for all specification as the likelihood ratio and Wald tests always reject the null hypotheses of an episode-specific variance component and of correlation between the errors of the FAIL2 and $A N C H O R$ equations. In the case of $R A T J O$, instead, we also present the random effects estimates for all specifications and those with the Heckman correction for the model with only initial condition and external variables. All estimation techniques yield very similar results. We conducted the specification search by adding progressively blocks of variables as we did with FAIL1.

The overall fit of the model for FAIL2 is not as good as the one for FAIL1 but the regression with only exogenous controls and initial conditions still has a pseudo- $R^{2}$ of 0.315 . The addition of political economy variables increases substantially the fit of this regression raising the pseudo- $R^{2}$ to 0.501 . Also the share of outcomes correctly predicted increases above 85 percent with both a conventional 0.5 threshold and a threshold equal to the sample frequency of failure $(0.413)$. With a threshold equal to 0.2 , the model would correctly predict 90 percent of failures and 70 percent of successes. Taking adjustment variables into account further increases the pseudo- $R^{2}$ but only to 0.549 and leaves the predictive ability

${ }^{47}$ In terms of outcomes, it can be proxied by the evolution of the current account balance, although this variable will also be affected by developments in external demand, international interest rates and the terms of trade. 
Table 7. Dynamic FAIL2 Estimates

(Heteroskedastic corrected standard errors in parenthesis)

\begin{tabular}{|c|c|c|c|}
\hline & (1) & (2) & (3) \\
\hline \multicolumn{4}{|l|}{ Initial conditions: } \\
\hline \multirow[t]{2}{*}{$\pi_{\tau .}$} & $-3.793 * * *$ & $-6.950 * * *$ & $-9.447 * * *$ \\
\hline & $(0.877)$ & $(1.465)$ & $(1.443)$ \\
\hline \multirow[t]{2}{*}{$R E S_{T-1}$} & $0.081 *$ & $0.123^{* * *}$ & \\
\hline & $(0.037)$ & $(0.041)$ & \\
\hline \multirow[t]{2}{*}{$G B_{\tau-f}$} & 1.479 & $4.933 * *$ & \\
\hline & $(1.282)$ & $(1.996)$ & \\
\hline \multirow[t]{2}{*}{$G D P_{r-1}$} & -4.328 & & \\
\hline & $(2.948)$ & & \\
\hline$Y_{G A P_{T-1}}$ & $\begin{array}{l}4.301 \\
(1.853)\end{array}$ & $\begin{array}{l}7.770^{* *} \\
(2.575)\end{array}$ & \\
\hline ANCIIOR & $\begin{array}{r}-0.633 \\
(0.419)\end{array}$ & $\begin{array}{l}-2.194 * * * \\
(0.489)\end{array}$ & $\begin{array}{l}-2.510^{* * *} \\
(0.503)\end{array}$ \\
\hline$O P E N K A_{T-1}$ & $-1.017 * *$ & $-2.116^{* * *}$ & $-1.636^{* *}$ \\
\hline \multicolumn{4}{|l|}{ External controls: } \\
\hline$U S i_{T+i}$ & $\begin{array}{l}9.721 * \\
(5.566)\end{array}$ & $\begin{array}{l}26.227^{* * *} \\
(6.199)\end{array}$ & $\begin{array}{l}24.887^{* * *} \\
(7.199)\end{array}$ \\
\hline$X D E M_{T+1}-X D E M_{T}$ & $\begin{array}{l}-6.432 * * * \\
(2.301)\end{array}$ & $\begin{array}{l}-5.903 * * \\
(2.614)\end{array}$ & $\begin{array}{l}-4.180 * \\
(2.515)\end{array}$ \\
\hline \multicolumn{4}{|l|}{ State dependence: } \\
\hline YEARS $x>10$ & $\begin{array}{l}0.146^{* * *} \\
(0.056)\end{array}$ & $\begin{array}{l}0.241^{* * *} \\
(0.063)\end{array}$ & $\begin{array}{l}0.270^{* * *} \\
(0.069)\end{array}$ \\
\hline$F A I L 2_{T * t-1} \quad(l=2,3)$ & $\begin{array}{l}1.111 * * * \\
(0.317)\end{array}$ & $\begin{array}{l}0.926^{* *} \\
(0.371)\end{array}$ & $\begin{array}{l}0.619^{*} \\
(0.374)\end{array}$ \\
\hline \multicolumn{4}{|l|}{ Political institutions: } \\
\hline$D U R R E G_{T}$ & & $\begin{array}{l}-0.039 * * * \\
(0.011)\end{array}$ & $\begin{array}{l}-0.045 * * * \\
(0.011)\end{array}$ \\
\hline$X \operatorname{CONST}_{T+i-1}$ & & $\begin{array}{l}0.755^{* * *} \\
(0.151)\end{array}$ & $\begin{array}{l}0.968 * * * \\
(0.143)\end{array}$ \\
\hline$M A J_{T+i-i}$ & & $\begin{array}{l}-3.062 * * * \\
(0.686)\end{array}$ & $\begin{array}{l}-3.175 * * * \\
(0.538)\end{array}$ \\
\hline \multicolumn{4}{|l|}{ Political conditions: } \\
\hline$C E_{Y B A R S C=3}$ & & $\begin{array}{l}-1.414 * * * \\
(0.295)\end{array}$ & $\begin{array}{l}-1.279 * * * \\
(0.349)\end{array}$ \\
\hline POLNCOH ${ }_{T+i-1}$ & & $\begin{array}{l}-0.616^{* * *} \\
(0.187)\end{array}$ & $\begin{array}{l}-0.898 * * * \\
(0.204)\end{array}$ \\
\hline $\begin{array}{l}\text { Nonpolicy macro variables: } \\
G D P_{T+t-j}\end{array}$ & & & $-7,034 * * *$ \\
\hline$Y G A P_{\tau+\dot{\prime} \cdots}$ & & & $\begin{array}{r}(3.148) \\
6.841 \\
(4607)\end{array}$ \\
\hline$R E S_{1+t-1} \quad R E S_{Y-1}$ & & & $\begin{array}{l}(4.607) \\
-0.273 * * * \\
(0.060)\end{array}$ \\
\hline $\begin{array}{l}\text { Policy macro variables: } \\
G B_{T+5-1}-G B_{r}\end{array}$ & & & $\begin{array}{r}-3.431 \\
(6.678)\end{array}$ \\
\hline$D C_{T+t-1}$ & & & $\begin{array}{l}0.346 * * * \\
(0.073)\end{array}$ \\
\hline Constant: & $\begin{array}{r}0.130 \\
(0.702)\end{array}$ & $\begin{array}{r}-1.022 \\
(0.725)\end{array}$ & $\begin{array}{r}-0.492 \\
(0.908)\end{array}$ \\
\hline$\chi_{2}^{2}$ of LR test of: $\rho=0$ & 0.000 & 0.000 & 0.000 \\
\hline$\chi^{2}$ of Wald test of: $\delta=0$ & 0.093 & 0.082 & 0.000 \\
\hline Pseudo $R^{2}$ & 0.315 & 0.501 & 0.562 \\
\hline Efron's $R^{2}$ & 0.358 & 0.555 & 0.601 \\
\hline Percent of hits $\left(p^{*}=0.5\right)$ & 75.0 & 85.3 & 85.3 \\
\hline Percent of hits ( $p^{*}=0.413$ ) & 78.0 & 86.0 & 84.7 \\
\hline Percent of hits $\left(p^{*}=0.2\right)$ & 69.3 & 78.7 & 78.0 \\
\hline Percent of $F A I L I=I$ hits $\left(p^{*}=0.2\right)$ & 93.6 & 90.3 & 93.6 \\
\hline Percent of $F A L L l=O$ hits $\left(p^{*}=0.2\right)$ & 52.3 & 70.5 & 67.1 \\
\hline Number of observations & 150 & 150 & 150 \\
\hline
\end{tabular}

Note: Data are annual. Three $\left({ }^{* *}\right)$, two $\left({ }^{* *}\right)$, and one $\left({ }^{*}\right)$ asterisks mark statistical significance at respectively 1,5 , and 10 perecml levels. 
Table 8. Dynamic RATIO Estimates

(Heteroskedastic corrected standard errors in parenthesis)

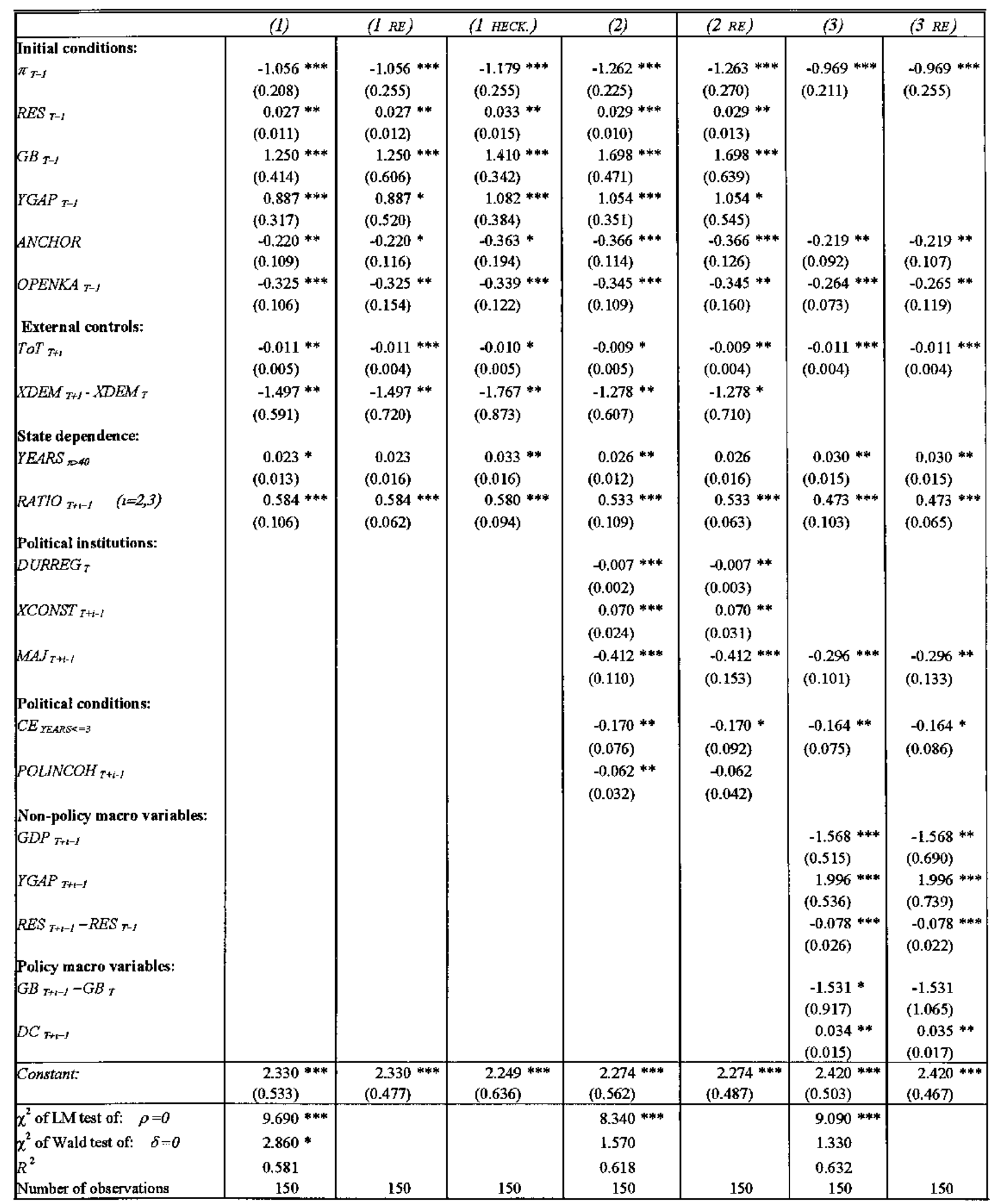

Note: Data are annual. Three $\left({ }^{* * *}\right)$, two $\left({ }^{* *}\right)$, and one $\left({ }^{*}\right)$ asterisks mark statistical significance at respectively, 1,5 , and 10 percent levels. 
of the model almost unchanged. The fit of the model for RATTO with only exogenous controls and initial conditions is extremely good with an $R^{2}$ of 0.581 . The addition of political economy and adjustment variables increases the $R^{2}$ only marginally to 0.618 and 0.632 . respectively.

\section{Initial conditions, external shocks, and state dependence}

The estimates with FAIL2 and RATIO confirm the indications obtained from the FAILI regressions on the most relevant initial and external conditions. Higher pre-stabilization inflation, lower international reserves, and a negative output gap significantly increase the likelihood of success, confirming the evidence in support of the "crisis hypothesis." ${ }^{48} \mathrm{We}$ also find confirmation of the increased chances of success associated with an exchange-ratebased stabilization. In the case of FAIL2, however, the $A N C H O R$ dummy becomes statistically significant only after we control for political economy variables. An open capital account prior to stabilization continues to reduce the probability of failure, but we no longer find evidence that it makes the stabilization more vulnerable to interest rate shocks, nor do we find that an open current account matters. Among external conditions, a reduction in import demand from trading partners significantly increases the probability of failure for both $F A I L 2$ and RATIO. The level of U.S. interest rates, instead, matters only with FAIL2, while terms of trade shocks $\left(T O T_{T+i}\right)$ are a good predictor of the evolution of RATTO. Pre-stabilization and insample state dependence are important with both FAIL2 and RATIO. The number of prestabilization years with inflation above 40 percent increases both measures of failure. The statistical significance of $F A I L 2_{T+i-1}$ and $R A T I O_{T+i-1}$ is an indication that failure (success) in any of the post-stabilization years tends to be followed by another failure (success). Contrary to the estimates with $F A I L I$, the in-sample state dependence remains statistically significant even after controlling for the adjustment variables.

\section{Political economy variables}

Column (2) in Tables 7 and 8 shows that the same set of political economy variables contributes to explain FAIL2 and RATIO. Only two, however, remain statistically significant in the $R A T I O$ regression when we add nonpolicy and policy adjustment variables. As in the FAILI estimates, the more durable is the political regime and the fewer are the constraints on the chief executive the less likely is the stabilization to fail. Democracies with majoritarian electoral rules $\left(M A J_{T+i-1}\right)$ are also less likely to fail (as already mentioned, this coefficient could not be estimated for $F A L L 1$ because all majoritarian regimes were successful under that measure of failure). The regressions with FAIL2 and RATIO also confirm the surprising result that less politically cohesive regimes are less likely to fail, which, as discussed in Subsection III.A, can be attributed to the successful stabilizations implemented by some "national unity" governments.

${ }^{48}$ In addition, there is some indication that also a negative pre-stabilization fiscal balance $\left(G B_{T-1}\right)$ contributes to the likelihood of success, suggesting that a fiscal crisis can also play a role. 


\section{Policy and nonpolicy macroeconomic variables}

The estimates in Tables 7 and 8 confirm the relevance of most nonpolicy adjustment variables that were found statistically significant in the FAIL1 regressions. An increase in international reserves from year T-1 $\left(R E S_{T+i-1}-R E S_{T-1}\right)$ and lagged GDP growth $\left(G D P_{T+i-1}\right)$ tend to reduce the chances of failure. In addition, the more positive is the output gap $\left(Y G A P_{T+i-1}\right)$ in the stabilization year and the following years the more likely is a stabilization to fail. This result appears consistent with Orphanides' "opportunistic" theory of disinflation according to which a large negative output gap could create a favorable condition for a successful disinflation by permitting higher noninflationary growth in the post-stabilization years.

Among the policy variables, higher domestic credit growth tends to increase the likelihood of failure in both the FAIL2 and RATIO regressions. Fiscal adjustment is, instead, significant only in the $R A T I O$ regression. The lack of significance of the fiscal adjustment in the FAIL 2 regression can be interpreted as indicating that some other regressors-most likely, political economy variables and adjustment variables such as GDP growth and domestic credit growth - fully account for what would otherwise be the contribution of fiscal policy adjustment to the success of inflation stabilization.

\section{Robustness to Different Sample Selection Criteria}

In Table 9 we present dynamic pooled regression estimates obtained by running more parsimonious specifications for FAIL1, FAIL2, and RATIO on the smaller dataset corresponding to Easterly (1996). The statistical tests accept the null hypothesis of a zero share of variance attributable to episode-specific effects, thus indicating that pooled estimates are adequate. The smaller size of the sample prevents us, instead, from reliably estimating the models with the endogeneity correction for the anchor. The small sample size also suggests that results should be interpreted with caution. In particular, we had to drop some variables in some probit specifications because they perfectly predicted success or failure. The main purpose of this estimation exercise is then only to have an approximate indication of whether a different selection criterion for the stabilization episodes would have led us to very different conclusions on the determinants of stabilization failures.

The estimates based on Easterly's sample broadly confirm our previous results. The fit of the three models is surprisingly good with pseudo- $R^{2}$ equal to 0.806 for FAIL1 and 0.584 for $F A I L 2$, and an $R^{2}$ of 0.765 for $R A T I O$. Higher pre-stabilization inflation continues to increase the likelihood of success yielding further support to the "crisis hypothesis." The association between ERBS and successful stabilizations is also confirmed, while a long history of high inflation remains a predictor of failure. In this subsample, we do not find, instead, evidence that openness matters. 


$$
-51-
$$

Table 9. Dynamic Pool Estimates on Easterly's (1996) Sample (Heteroskedastic corrected standard errors in parenthesis)

\begin{tabular}{|c|c|c|c|}
\hline & FAILI & FAIL2 & RATIO \\
\hline \multicolumn{4}{|l|}{ Initial conditions: } \\
\hline$\pi_{T-1}$ & $\begin{array}{l}-35.470 * * \\
(17.660)\end{array}$ & $\begin{array}{l}-12.913^{* * *} \\
(2.528)\end{array}$ & $\begin{array}{l}-1.456^{* * *} \\
(0.222)\end{array}$ \\
\hline$G D P r-1$ & & $\begin{array}{l}-18.747^{* * *} \\
(5.418)\end{array}$ & \\
\hline$A N C H O R$ & $\begin{array}{l}-9.935^{* *} \\
(4.218)\end{array}$ & $\begin{array}{l}-1.249^{* * *} \\
(0.456)\end{array}$ & $\begin{array}{l}-0.311^{* * *} \\
(0.119)\end{array}$ \\
\hline \multicolumn{4}{|l|}{ External controls: } \\
\hline$U S i_{T+1}$ & $\begin{array}{l}109.048 * \\
(59.797)\end{array}$ & & \\
\hline $\operatorname{ToT}_{T+i}$ & & $\begin{array}{l}-0.103^{* *} \\
(0.046)\end{array}$ & $\begin{array}{l}-0.036^{* * *} \\
(0.011)\end{array}$ \\
\hline$X D E M_{Y+1}-X D E M_{T}$ & $\begin{array}{l}-48.034^{* *} \\
(23.950)\end{array}$ & & \\
\hline \multicolumn{4}{|l|}{ State dependence: } \\
\hline$Y E A R S_{n>40}$ & $\begin{array}{l}0.620^{* *} \\
(0.287)\end{array}$ & $\begin{array}{l}0.235^{* * *} \\
(0.062)\end{array}$ & $\begin{array}{r}0.021 \\
(0.014)\end{array}$ \\
\hline RATIO $_{T+i-1} \quad(l=2,3)$ & & & $\begin{array}{l}0.425^{* * *} \\
(0.105)\end{array}$ \\
\hline Political institutions: & & & \\
\hline$D U R R E G_{T}$ & & $\begin{array}{r}-0.021 \\
(0.013)\end{array}$ & \\
\hline$X C O N S T_{T+i-J}$ & & $\begin{array}{l}0.482 * * * \\
(0.137)\end{array}$ & $\begin{array}{l}0.063 * \\
(0.032)\end{array}$ \\
\hline Political conditions: & & & \\
\hline$C E_{Y E A R S<=3}$ & & $\begin{array}{l}-1.475^{* * *} \\
(0.342)\end{array}$ & $\begin{array}{l}-0.370^{* * *} \\
(0.108)\end{array}$ \\
\hline POLINCOH ${ }_{T+i-1}$ & & $\begin{array}{l}-0.819^{* * *} \\
(0.227)\end{array}$ & $\begin{array}{r}-0.050 \\
(0.038)\end{array}$ \\
\hline $\operatorname{SOCCONF}_{T+1-1}$ & $\begin{array}{l}1.065^{* * *} \\
(0.289)\end{array}$ & & \\
\hline $\begin{array}{l}\text { Nonpolicy macro variables: } \\
G D P_{T+i-1}\end{array}$ & & & $\begin{array}{l}-2.015^{*} \\
(1.132)\end{array}$ \\
\hline$R E S_{T+t-1}-R E S_{T-1}$ & $\begin{array}{l}-0.589^{* * *} \\
(0.140)\end{array}$ & $\begin{array}{l}-0.393^{* * *} \\
(0.127)\end{array}$ & $\begin{array}{l}-0.131^{* *} \\
(0.057)\end{array}$ \\
\hline Policy macro variables: & & & \\
\hline $\begin{array}{l}G B_{T+1-1}-G B_{T} \\
D C_{T+1-1}\end{array}$ & $\begin{array}{c}-30.776^{* * *} \\
(10.820) \\
0.625^{*} \\
(0.334) \\
\end{array}$ & $\begin{array}{l}-8.589 * \\
(4.818)\end{array}$ & $\begin{array}{l}-2.700^{* *} \\
(1.210)\end{array}$ \\
\hline Constant: & $\begin{array}{r}0.473 \\
(2.406) \\
\end{array}$ & $\begin{array}{l}15.016^{* * *} \\
(5.419)\end{array}$ & $\begin{array}{l}5.120^{* * *} \\
(1.174) \\
\end{array}$ \\
\hline $\begin{array}{l}\chi^{2} \text { of LR / LM test of: } \rho=0 \\
\text { Pseudo } R^{2} / R^{2} \\
\text { Number of observations }\end{array}$ & $\begin{array}{r}0.840 \\
0.806 \\
81 \\
\end{array}$ & $\begin{array}{r}0.000 \\
0.584 \\
81 \\
\end{array}$ & $\begin{array}{r}0.630 \\
0.765 \\
81 \\
\end{array}$ \\
\hline
\end{tabular}

Note: Data are annual. Three $\left({ }^{* * *}\right)$, two $\left({ }^{* *}\right)$, and one $\left({ }^{*}\right)$ asterisks mark statistical significance at respectively 1,5 , and 10 percent levels. 
Among the exogenous controls, higher U.S. interest rates $\left(U S i_{T+i}\right)$, and a reduction in import demand from trading partners between period $T$ and $T+I\left(X D E M_{T+1}-X D E M_{T}\right)$ significantly increase the probability of failure with $F A I L I$, while terms of trade shocks are more important with FAIL2 and RATIO.

In the estimates with the dichotomous variables, we find little evidence of in-sample state dependence as $F A I L 1_{T+i-1}$ and $F A I L 2_{T+i-1}$ are dropped from the set of regressors. $R A T I O_{T+i-1}$ remains, instead, statistically significant.

Some political economy variables play a role also in this smaller dataset. Our measure of increasing social tensions contributes to explain stabilization failures as measured by FAIL1. The constraints on the executive authority, political cohesion, and the number of years the chief executive has been in power are statistically significant determinants of both FAIL2 and $R A T I O$. In the case of $F A I L 2$, the duration of the political regime at the start of stabilization also plays some role.

Among the adjustment variables, higher international reserves and improved fiscal balances reduce the chances of failure with all three measures, whereas domestic credit growth is relevant only for FAILI.

\section{Summary AND CONCLUSIONS}

This paper highlights three sets of factors that can help predict the failure of high inflation stabilizations. External shocks, initial conditions-including the choice of the nominal anchor and the degree of openness of the economy-and political conditions and institutions predict correctly about 85 percent of the stabilization outcomes, measured by the two dichotomous variables, and explain about 60 percent of the variance of our continuous measure. We also find that many of these factors retain their significance even after controlling in the regressions for the evolution of post-stabilization macro variables such as GDP growth, real exchange rate developments, changes in international reserves, and monetary and fiscal adjustment.

"Good luck" is important. We find that adverse external shocks such as changes in U.S. interest rates, imports demand from trading partners, and terms of trade, significantly contribute to stabilization outcomes. Among the initial conditions, our findings strongly support the "crisis hypothesis" indicating that higher pre-stabilization inflation tends to be associated with a smaller probability of failure. The openness of the capital account at the beginning of the stabilization tends, instead, to reduce the chances of failure but we also find some indication that it may significantly amplify the effect of international interest rate shocks. We only find weak evidence that an open current account contributes to a successful disinflation. 
We find strong evidence in support of initial state dependence with countries having a longer history of high inflation at the start of the stabilization being more likely to fail. This evidence is also consistent with the presence of institutions, such as indexation, in chronically high inflation countries that make stabilization more difficult. We also find some support for in-sample state dependence indicating that stabilization that succeed (fail) at the beginning of our three-year window are ceteris paribus more likely to continue to succeed (fail) in the following year. In our benchmark estimates, however, past in-sample outcomes are no longer statistically significant predictors of success when we control for the poststabilization path of nonpolicy and policy variables, suggesting that a successful adjustment can in some cases overcome the effects of state dependence.

We also find that exchange-rate based stabilizations are less likely to fail over the following three years, no matter whether we control or not for the endogeneity of the anchor. As this effect remains statistically significant even after controlling for monetary and fiscal adjustment, we conclude that exchange rate anchors may play a role in coordinating expectations as suggested by some theoretical contributions. An important caveat of this result is, however, that a significant effect of exchange rate anchors can only be identified after controlling for other initial conditions, external shocks, and, in the case of our second dichotomous measure of failure FAIL2, political institutions and conditions. A simple bivariate analysis indicates, in fact, that the frequency of failure among ERBS is similar to that of stabilizations with other nominal anchors. The important policy implication is that an exchange rate anchor alone cannot guarantee success and that other initial and political conditions should be in place. $^{49}$

Political institutions are important determinants of stabilization failures. We find that the more constrained the authority of the chief executive is the higher is the likelihood of failure. Importantly, we show that this result is not driven by some successful stabilizations implemented by nondemocracies in our sample but also holds for the subsample of democracies, yielding indirect support to recent political economy theories that point to the greater ability of presidential regimes to limit government expenditure. We show, however, that, to identify this effect, it is important to use the finer classification of executive authority constraints from the POLITY IV dataset, while a simple zero-one dummy for presidential regimes was not statistically significant. We also find that majoritarian electoral rules within the subset of democratic countries tend to reduce the likelihood of failure. As our sample is characterized by several political regime transitions from and to democracy, as well as

${ }^{49}$ Future research may verify whether these results are robust to the different classification of exchange rate regimes proposed by Reinhart and Rogoff (2002). Their sample needs, however, to be extended to cover five countries (nine stabilization episodes) included in our study (Bangladesh, Mozambique, Sao Thome \& Principe, Sierra Leone, and Somalia). 
changes in the degree of democracy, we also check whether "younger" political regimes are more likely to fail finding support for this hypothesis, which is related to the prediction that political instability and inflation are associated.

Political conditions are also important. Chief executives that have been in power for less than three years are more likely to succeed, consistently with reputation models that predict new governments would choose lower levels of inflation independently from their ability to pre-commit or preferences. We find mixed evidence on "war of attrition" models. While increases in an indicator of social tensions significantly augment the likelihood of failure in our benchmark regressions, we do not find any evidence that more polarized governments are more likely to fail. Our data actually provide support to the opposite prediction, indicating that more polarized governments are more likely to succeed. This surprising result reflects the success in stabilizing inflation of some "national unity" governments, such as Israel in 1986, characterized by high polarization scores, and suggests that the end of war of attritions may sometimes be associated with a cooperative agreement among the major parties rather than with one of the groups involved in the war of attrition imposing the redistributive costs of stabilization on the other. We also find that a long history of high inflation increases the probability of failure, consistently with an interpretation based on credibility and reputational effects, whereas war-of-attrition models would predict that the longer is the war of attrition the more likely is one of the parties involved to concede and stabilization to succeed.

While providing a number of interesting insights, this paper has limits that future research could try to overcome. These are associated mainly with the sample selection issue, the small number of observations, and the estimation technique. ${ }^{50}$ As discussed in Subsection II.B, our results on the determinants of inflation stabilization failures are valid within the set of stabilizations that are sufficiently successful at the outset to be selected by our numerical rule. Our conclusions cannot apply, instead, to the larger set of all attempts at stabilizing inflation nor to inflation stabilization episodes selected with alternative rules. As a robustness check, we re-estimate our model on the subsample of inflation stabilizations selected by Easterly (1996) and we find confirmation of our main results (Subsection III.C).

\footnotetext{
${ }^{50}$ Future research may also try to overcome some data limitations. In spite of the large set of potential determinants of stabilization failure that we consider, there are a few important ones that we neglect. Measures of income inequality could not be used to test "war of attrition" models because they were missing for some countries in the sample. Similarly, we could not find a complete set of indicators of central bank independence. Finally, the role of financial development, whose association with inflation has been recently studied by Albanesi (2000), cannot be properly assessed because the values taken by standard measures of financial development--such as ratios of M2 or bank credit to GDP_tend to be closely related with inflation developments before and after inflation stabilizations with a causal relationship trivially running from the latter to the former.
} 
Future research should consider verifying our findings on datasets with inflation stabilization episodes selected with different criteria such as, for example, that of Fischer, Sahay, and Végh (2002). We experimented with the part of this dataset (29 episodes) overlapping with ours and obtained broadly similar results, but a proper test - which is beyond the scope of this paper-would require using their full dataset.

Even though our dataset is larger than those used in previous studies, it remains a small dataset. One issue is the direct effect of the sample size on the statistical significance of the estimated coefficients. Extending the post-stabilization horizon by one or two years may look like a sensible solution to this problem but this solution has some shortcomings. As already mentioned, there is a need not to have a post-stabilization horizon so long that inflation performance in the final years is largely unrelated to the stabilization. Moreover, for countries with more than one stabilization episode, lengthening the horizon would make observations corresponding to different stabilization episodes overlap as they would enter the dataset twice, first as the final years of an earlier episode and then as the initial years of a new one. In sum, a three year post-stabilization horizon (actually a 4-year window if the stabilization year is included) looks like a sensible middle ground and the classification of almost all episodes is confirmed when we extend the horizon to five years. A three-year horizon is also consistent with the view held by several researchers that the eventual fate of most stabilizations is determined within their first three to five years (Reinhart and Végh, 1995; Uribe, 1999). ${ }^{51}$

A second issue related to the sample size is that many potential determinants of the stabilization outcome, especially variables measuring political institutions, are relatively time-invariant. In a dataset that forces us to separate democracies from nondemocracies, this leaves us with very few observations determining the outcome (for example, only six democracies in our sample have majoritarian electoral systems). This problem has no easy solution and is common to many political economy studies, which have usually been based on cross-country datasets with few observations. However, the panel structure of our dataset and the relatively large time variation of some political institutions-resulting from the frequent political regime changes-provides us with a sample in which political economy variables may actually show more variation than in other studies.

${ }^{51}$ A more drastic alternative solution to the sample size problem would have been to use a large panel with long time-series of data for each country and apply dynamic panel data methods to identify short-term dynamics and long-term relationships between inflation and other variables. While this approach would have significantly reduced the degrees of freedom problem and simplified the specification search, we believe that the structural breaks associated with inflation stabilization attempts would have strongly affected the results, as statistical relationships between variables are likely to be significantly different around the time of inflation stabilization when announcements and policy signals play a key role. 
This paper uses a variety of estimation techniques described in Section II to take into account the dichotomous or continuous nature of our stabilization failure measures, possible unobservable heterogeneity across episodes, and the endogenous choice of the nominal anchor. Recently, Persson, and Tabellini (2001b) have used nonparametric matching estimates techniques to overcome some of the problems associated with empirical work on small political economy datasets, such as the biases due to systematic selection and possible nonlinearities. They conducted this exercise, however, under the assumption of conditional independence, which is exactly the assumption we try to test by using a bivariate probit and Heckman's procedure when we control for the possible endogeneity of the anchor. As we found, however, little evidence of endogeneity, it might be interesting in future research to apply matching techniques also to our dataset. To estimate a dynamic probit on our dataset, future research may also consider using simulated-based inference methods-such as the maximum smoothly simulated likelihood method recently applied by Falcetti and Tudela (2001) to the study of currency and banking crises or the Markov chain Monte Carlo method applied to the issue of state failures by Beck, and others (2001). The small sample size and the large number of potential regressors might, however, make it difficult to use these advanced techniques on our dataset. 


\section{Episode Selection}

Since Hamann (2001) selected stabilization episodes exclusively on the basis of inflation performance, he sought to rule out the possibility that they represented positive supply shocks, rather than bona-fide stabilization episodes. He used two checks for this purpose. The first was to look for the existence of IMF programs during a period of up to two years prior to the stabilization date identified in Table 1. Of the 51 episodes 38 were preceded by, or coincided with, an IMF Fund program. For the remaining 13 episodes, a second check consisted on looking for independent evidence in the literature that a stabilization plan had indeed been put in place at around the time identified in Table 1. For eight of these cases, there is plenty of supporting evidence: Argentina 1980 actually represents its tablita experiment, which ran from December 1978 to February 1981; Brazil 1990 is president Collor's stabilization plan of 1990-91; Indonesia's "stabilization and rehabilitation" program started in 1966 is documented by Azis (1994); the Israeli stabilization plan has been analyzed extensively-Bruno and Piterman (1988) is the first of several studies dealing with the Israeli stabilization; Iceland's two stabilization plans are reviewed by Andersen and Guômundsson (1998); and Ghana's strategy to mop up excess liquidity in 1978 is documented by Sowa (1993). Other episodes are not well documented in the literature but clearly constitute bona-fide stabilization programs: Lebanon's 1993 stabilization is part of the economic reconstruction plan started in 1991 following the Taif peace treaty, and Ecuador 1994 reflects the efforts of that country's authorities to bring down inflation through the active use of the exchange rate as a tool to anchor expectations about inflation. Thus, for only four of the 51 episodes there is no independent evidence of the adoption of a stabilization plan: Lebanon 1988, Sierra Leone 1992, Syria 1988 and Guinea Bissau 1993.

An alternative to a rules-based method for selecting episodes would have been a comprehensive review of the history of those countries, aimed at identifying periods in which governments put in place anti-inflation economic programs. This alternative route would necessarily entail some controversial judgments regarding, for instance, whether to exclude programs that could not be considered serious attempts at disinflation, or programs that were abandoned soon after they were implemented. Furthermore, in most cases, identifying the precise timing of stabilization episodes could be equally arbitrary. It is not always the case that inflation stabilization programs have a clearly identifiable start date, with the exceptions being perhaps those in which the exchange rate played a central role and its future path was announced along with other measures. ${ }^{52}$ Moreover, it is often the case that inflation is successfully brought down after more than one attempt and, even in those cases, it is not entirely clear when a given stabilization plan ended and the next one began.

\footnotetext{
${ }^{52}$ Even in those cases, other stabilization policies may have been put in place before the announcement of a path for the exchange rate, thus obscuring the timing of stabilization.
} 
Another alternative would have been to rely on existing work documenting stabilization programs in high inflation countries. But those studies are not likely to provide a comprehensive account of stabilization episodes. Furthermore, doubts about the precise timing of the stabilization programs and consistency across countries of the methodology for selecting relevant episodes are not likely to be resolved by relying on a survey of existing studies of stabilization experiences.

Thus, in order to test the robustness of our results to the chosen selection rule, in Subsection III.C we show the results arising from re-estimating our main specifications using Easterly's sample of countries. A comparison of the results generated by each of these samples will hopefully shed some light about whether the identified stylized facts are robust to changes in the precise statistical definition of a stabilization episode. 


\section{Sources of Data}

The IMF's International Financial Statistics was the main source of data for all variables, except for the current account and the real exchange rate. Current account data from the IMFs WEO database was used, except for one case (Brazil 1963-69) where, due to the lack of data on the current account, trade balance data from IFS had to be used. In several instances, data from national sources were needed to fill some gaps (especially in the oldest episodes), or when IFS data contained breaks (typically in the case of the population variable, which was needed to compute GDP per capita). The fiscal data refers to the central government. For the real exchange rate, a multilateral real effective exchange rate variable was available from an IMF's internal database from 1980 onwards. For countries for which this variable was not available, or in cases where data prior to 1980 was needed, a bilateral real exchange rate vis-à-vis the U.S. dollar was constructed. Political economy variables are from the World Bank Dataset on Political Institutions (DPI), the POLITY IV dataset, and Banks' Cross-National Time-Series Data Archive. Information in various issues of Banks' "Political Handbook of the World" was used to eliminate missing values in these datasets and in the series of political and electoral regimes provided by Guido Tabellini. In most cases, we added São Tomé and Príncipe to the existing datasets by following as closely as possible the methodology used for other countries. In the POLITY IV dataset, we also interpolated the "transition" codes (-88), as suggested in the users manual; furthermore, we recoded ourselves, using the methodology spelled out in the users manual, some observations corresponding to Lebanon that the POLITY IV dataset had coded as "interruption" (-66) or "interregnum" (-77), in order to avoid missing values. 


\section{References}

Aghevli, B., M. Khan, and P. Montiel, 1991, Exchange Rate Policy in Developing Countries: Some Analytical Issues, IMF Occasional Paper No. 78, (Washington: International Monetary Fund).

Albanesi, S., 2000, "Inflation and Inequality," unpublished; Northwestern University.

Alesina, A, and A. Drazen, 1991, "Why Are Stabilizations Delayed?," American Economic Review, Vol. 81, pp. 117-88.

Alfaro, L., 1999, "Why Governments Implement Temporary Stabilization Programs," Journal of Applied Economics, Vol. 2, pp. 211-45.

Amemiya, T., 1985, Advanced Econometrics, (Cambridge, Massachusetts: Harvard University Press).

Anderson, T. W., and C. Hsiao, 1981, "Estimation of Dynamic Models with Error Components," Journal of the American Statistical Association, Vol. 76, pp. 598-606.

Arellano, M., and S. Bond, 1991, "Some Tests of Specification for Panel Data: Monte Carlo Evidence and an Application to Employment Equations," Review of Economic Studies, Vol. 58, pp. 277-97.

Ball, L., 1994, "What Determines the Sacrifice Ratio?," ed. by N.G. Mankiw in Monetary Policy, NBER Studies in Business Cycles, Vol. 29, (Chicago: University of Chicago Press).

Barro, R. J., 1986, "Reputation in a Model of Monetary Policy with Incomplete Information," Journal of Monetary Economics, Vol. 17, pp. 3-20.

Beck, N., D. Epstein, S. Jackman, and S. O'Halloran, 2001, “Alternative Models of Dynamics in Binary Time-Series Cross-Section Models: The Example of State Failure," paper prepared for the 2001 Annual Meeting of the Society for Political Methodology, (Atlanta, Georgia: Emory University).

Bertocchi, G., and F. Canova, 1996, "Did Colonization Matter for Growth? An Empirical Exploration into the Historical Causes of Africa's Underdevelopment," Universitat Pompeu Fabra Economics Working Paper No. 202, (Barcelona, Spain: Iniversitat Pompeau Fabra).

Calvo, G., L. Leiderman, and C. Reinhart, 1993, "Capital Inflows and Real Exchange Rate Appreciation in Latin America: The Role of External Factors," Staff Papers, Vol. 40, pp. 108-51, (Washington: International Monetary Fund). 
Calvo, G., and C. Végh, 1994, "Inflation Stabilization and Nominal Anchors," Contemporary Economic Policy, Vol. 12, pp. 35-45.

_ 1999, "Inflation Stabilization and BOP Crises in Developing Countries," NBER Working Paper No. 6925, (Cambridge, Massachussets: National Bureau of Economic Research).

Card, D., 2001, "Estimating the Return to Schooling: Progress on Some Persistent Econometric Problems," Econometrica, Vol. 69, No. 5, pp. 1127-60.

Cukierman, A., and Edwards, G. Tabellini, 1992, "Seigniorage and Political Instability," American Economic Review, Vol. 82, No. 3, pp. 537-55.

1988, "The End of the High Israeli Inflation: An Experiment in Heterodox Stabilization," in Inflation Stabilization: The Experience of Israel, Argentina, Brazil, Bolivia and Mexico, ed. by M. Bruno, G. di Tella, R. Dornbusch, and S. Fischer (Cambridge: MIT Press).

Dornbusch, R., 1991, "Credibility and Stabilization," Quarterly Journal of Economics, Vol. 106, No. 3, pp. 837-50.

Drazen, A., and W. Easterly, 2000, "Do Crises Induce Reform? A Simple Empirical Test of Conventional Wisdom," unpublished.

—, and V. Grilli, 1993, "The Benefit of Crises for Economic Reforms," American Economic Review, Vol. 83, pp. 598-607.

Easterly, W., 1996, "When is Stabilization Expansionary? Evidence from High Inflation," Economic Policy, No. 21, pp. 67-107.

M. Kremer, L. Pritchett, and L.H. Summers, 1993, "Good Policy or Good Luck? Country Performance and Temporary Shocks," NBER Working Paper No. 4474, (Cambridge, Massachusetts: National Bureau of Economic Research).

Efron, B., 1978, "Regression and ANOVA with Zero-One Data: Measures of Residual Variation," Journal of the American Statistical Association, Vol. 73, pp. 113-212.

Falcetti, E., and M. Tudela, 2001, "Modeling Currency Crises in Emerging Markets: A Dynamic Probit Model with Unobserved Heterogeneity and Autocorrelated Errors," paper presented at the 2001 European Economic Association meetings, Lausanne, Switzerland.

Fama, E., L. Fisher, M. Jensen, and R. Roll, 1969, "The Adjustment of Stock Prices to New Information," International Economic Review, Vol. 10, pp. 1-21. 
Fischer S., R. Sahay, and C. Végh, 2002, "Modern Hyper-and High Inflations," Journal of Economic Literature, (forthcoming).

- 1986, "Exchange Rate versus Money Targets in Disinflation," in his Indexing, Inflation and Economic Policy, (Cambridge, Massachusetts: MIT Press).

Giavazzi, F., and M. Pagano, 1986, "The Advantage of Tying One's Hands: EMS Discipline and Central Bank Credibility," CEPR Discussion Paper No. 135, (London, United Kingdom : Centre for Economic Policy Research).

Gould, D., 2001, "Does the Nominal Anchor Matter? Endogeneity in the Choice of a Stabilization Program," unpublished.

Greene, W. H., 2000, Econometric Analysis, (New Jersey: Prentice Hall,Upper Saddle River, Fourth edition.).

Hamann, A. J., 2001, "Exchange Rate Based Stabilization: A Critical Look at the Stylized Facts," Staff Papers, Vol. 48, pp. 111-38, (Washington: Interntional Monetary Fund).

Harberger, A., 1988, "World Inflation Revisited," in Economic Effects of the Government Budget, ed. by E. Helpman, A. Razin, and E. Sadka (Cambridge, Massachusetts: MIT Press).

Heckman, J. J., 1981, "Heterogeneity and State Dependence," in Studies in Labor Markets, ed. by S. Rosen (Chicago: University of Chicago Press), pp. 91-139

- 1979, "Sample Selection Bias as a Specification Error," Econometrica, Vol. 47, pp. 153-61.

Hsiao, C., 1986, Analysis of Panel Data, Econometric Society Monographs No. 11, (Cambridge: Cambridge University Press).

Kiguel, M., and N. Liviatan, 1992, "The Business Cycle Associated with Exchange RateBased Stabilization," The World Bank Economic Review, Vol. 6, pp. 279-305, (Washington: The World Bank).

Lane, P. R., 1997, "Inflation in Open Economies," Journal of International Economics, Vol. 42 , pp. $327-47$.

Maddala, G. S., 1983, Limited-Dependent and Qualitative Variables in Econometrics, Econometric Society Monographs No. 3, (Cambridg: Cambridge University Press).

McFadden, D., 1974, "The Measurement of Urban Travel Demand," Journal of Public Economics, Vol. 3, pp. 303-28. 
Milesi-Ferretti, G. M., R. Perotti, and M. Rostagno, 2001, "Electoral Systems and the Composition of Public Spending," Quarterly Journal of Economics, (forthcoming).

— and A. Razin, 1998, "Current Account Reversals and Currency Crises: Empirical Regularities," IMF Working Paper 98/99 (Washington: International Monetary Fund).

_ 1995, "A Simple Model of Disinflation and the Optimality of Doing Nothing," European Economic Review, Vol. 39, No. 7, pp. 1385-404.

Nordhaus, W., 1975, "The Political Business Cycle," Review of Economic Studies, Vol. 42, pp. $169-90$.

Orphanides, A., 1996a, "The Timing of Stabilizations," Journal of Economic Dynamics and Control, Vol. 20, pp. 257-79.

_- 1996b, “Optimal Reform Postponement," Economic Letters, Vol. 52 No. 3, pp. 299-307.

- - and D. Wilcox, 1996, "The Opportunistic Approach to Disinflation," Finance and Economics Discussion Series No. 36, (Washington: Federal Reserve Board).

Persson, T., 2001, "Do Political Institutions Shape Economic Policy?," NBER Working Paper No. 8214, (Cambridge, Massachussets: National Bureau of Economic Research). , and G. Tabellini, 2001a, "Political Institutions and Policy Outcomes: What are the Stylized Facts?," (unpublished).

_ 2001b, "Causal Effects of Institutions on Policy? Quasi-Experimental Evidence," paper presented at 2001 European Economic Association meetings, Lausanne, Switzerland.

—, and F. Trebbi, 2001, "Electoral Rules and Corruption," (unpublished; Institute for International Economic Studies).

— 1990, Macroeconomic Policy, Credibility, and Politics, (New York and Melbourne: Harwood Academic Publishers).

Reinhart, C., and K. Rogoff, 2002, "The Modern History of Exchange Rate Arrangements: A Reinterpretation," (unpublished, Washington: International Monetary Fund). and C. Végh, 1995, "Nominal Interest Rates, Consumption Booms, and Lack of Credibility: A Quantitative Examination," Journal of Development Economics, Vol. 46, pp. 357-78. 
Reinhart, C., and C. Végh, 1994, "Inflation Stabilization in Chronic Inflation Countries: The Empirical Evidence," (unpublished; Washington: International Monetary Fund).

Rogoff, K., 1987, "Reputational Constraints on Monetary Policy," Carnegie-Rochester Conference Series on Public Policy, Vol. 26, pp. 141-82.

Romer, D., 1993, “Openness and Inflation: Theory and Evidence," Quarterly Journal of Economics, Vol. 108, Issue No. 4, pp. 869-903.

Roubini, N., and J. Sachs, 1989, "Political and Economic Determinants of Budget Deficits in the Industrial Democracies," European Economic Review, Vol. 33, pp. 903-38.

Tornell, A., and A. Velasco, 1995, "Money-Based vs. Exchange Rate-Based Stabilization with Endogenous Fiscal Policy," NBER Working Paper No. 5300, (Cambridge, Massachussets: National Bureau of Economic Research).

Uribe, M., 1999, "Comparing the Welfare Costs and Initial Dynamics of Alternative Inflation Stabilization Policies," Journal of Development Economics, Vol. 59, No. 2, pp. 295-318.

Veiga, F. J., 2000, "Delays of Inflation Stabilization," Economics and Politics; Vol. 12, pp. 275-95.

— 1999 , "What Causes the Failure of Inflation Stabilization Plans?," Journal of International Money and Finance, Vol.18 No. 2, pp. 169-94.

Vickers, J., 1986, "Signaling in a Model of Monetary Policy with Incomplete Information," Oxford Economic Papers, Vol. 38, pp. 443-55.

Werner A. M., 1999, "Building Consensus for Stabilizations," Journal of Development Economics, Vol. 59 No. 2, pp. 319-36. 